\title{
AN ECOLOGICAL MODEL FOR CULTURALLY SENSITIVE CARE FOR OLDER IMMIGRANTS: BEST PRACTICES AND LESSONS LEARNED FROM ETHNO- SPECIFIC LONG-TERM CARE
}

\author{
by \\ Susan Barrass, BPAPM, Carleton University, 2006 \\ A Major Research Paper \\ presented to Ryerson University \\ in partial fulfillment of the requirements for the degree of \\ Master of Arts \\ in the Program of \\ Immigration and Settlement Studies
}

Toronto, Ontario, Canada, 2012

(C) Susan Barrass 2012 


\section{AUTHOR'S DECLARATION FOR ELECTRONIC SUBMISSION OF A MAJOR RESEARCH PAPER (MRP)}

I hereby declare that I am the sole author of this MRP. This is a true copy of the MRP, including any final revisions, as accepted by my examiners.

I authorize Ryerson University to lend this MRP to other institutions or individuals for the purpose of scholarly research.

I further authorize Ryerson University to reproduce this MRP by photocopying or by other means, in total or in part, at the request of other institutions or individuals for the purpose of scholarly research.

I understand that my MRP may be made electronically available to the public.

$\underline{\text { Susan Barrass }}$ 


\title{
AN ECOLOGICAL MODEL FOR CULTURALLY SENSITIVE CARE FOR OLDER IMMIGRANTS: BEST PRACTICES AND LESSONS LEARNED FROM ETHNO- SPECIFIC LONG-TERM CARE
}

\author{
Susan Barrass \\ Master of Arts, 2012 \\ Immigration and Settlement Studies \\ Ryerson University
}

\begin{abstract}
This qualitative and exploratory research project focuses on the way in which culturally appropriate care is being provided to older immigrants in ethno-specific longterm care settings in the Greater Toronto Area. Key Informant interviews with administrators of ethno-specific long-term care facilities were utilized in order to gather data on best practices and lessons learned for addressing the cultural needs of older immigrants living in long-term care. The research findings reinforce the need for ethnospecific long-term care programs, as well as culturally sensitive care in all programs, which alleviate the environmental stressors of institutional care and aging. Research recommendations point to a need for greater knowledge sharing within the long-term care sector, as well as increased education to service providers as to the historical context of the immigration and life experiences of ethno-specific groups in care. As well, there is a need for a shift in design of long-term care that addresses systemic issues of inequality that restrict how cultural care is delivered.
\end{abstract}

Keywords: long-term care; ethnicity; cultural care; older immigrant 


\section{ACKNOWLEDGEMENTS}

Thank you to Kenise Murphy Kilbride, whose guidance, patience and enthusiasm provided the encouragement I needed to complete this project, particularly on days when I didn't think I could. As well, thank you to Francis Hare for the valuable insight and contributions as my second reader.

Thank you also to all the participants who graciously shared their knowledge and experiences with me.

Finally, a special thank you to my parents and sisters, whose support and faith in me has gone above and beyond what anyone could ever ask for. I would not be at this stage were it not for your unconditional love and encouragement. 


\section{TABLE OF CONTENTS}

INTRODUCTION

DEFINITIONS 4

THEORETICAL FRAMEWORK

Leininger's theory of cultural care 6

Lawton's ecological model of aging and adaptability $\quad 7$

A New Theoretical Approach: An Ecological Model for Culturally Sensitive Care for Older
Immigrants

REVIEW OF THE LITERATURE $\quad 10$

CULTURAL CARE $\quad 15$

LAWTON'S ECOLOGICAL MODEL OF AGING AND ADAPTABILITY 18

METHODOLOGY 21

Methodological APPROACH 21

PARTICIPANT RECRUITMENT AND RESEARCH DESIGN

ANALYTICAL TEMPLATE $\quad 24$

CODING 24

FINDINGS 26

Best PRACTICES 26

Ease of Interaction $\quad 26$

Cultural norms

Continuity of cultural norms $\quad 30$

Spiritual continuity 34

Cultural understanding and preference $\quad 35$

Community 36

LESSONS LEARNED $\quad 38$

Systemic issues $\quad 38$

Cultural disconnect 41

Inter/intra-ethnic conflict 44

Effects of dementia 45

$\begin{array}{ll}\text { DISCUSSION } & 47\end{array}$

EASE OF INTERACTION

THE IMPORTANCE OF CULTURAL NORMS $\quad 48$

A NEED FOR BUILDING A SENSE OF COMMUNITY

SYSTEMIC ISSUES AND CULTURAL DISCONNECT

INTER/INTRA-ETHNIC CONFLICT

THE CHALLENGES OF DEMENTIA-RELATED DISORDERS IN PROVIDING CULTURALLY SENSITIVE CARE 52

UNANTICIPATED FINDINGS

LIMITATIONS OF THE RESEARCH

CONTRIBUTIONS TO THE LITERATURE AND AREAS FOR FURTHER RESEARCH

CONCLUSIONS AND RECOMMENDATIONS 59

APPENDICES $\quad 63$

$\begin{array}{ll}\text { REFERENCES } & 66\end{array}$ 


\section{INTRODUCTION}

Immigrants coming to Canada in later life stages face a number of distinct challenges to settlement and integration. Many older immigrants coming to Canada have traditionally done so under the family sponsorship class as parents and grandparents through the provisions of family reunification; therefore, they have not been subject to the same selection criteria as immigrants arriving through the economic class, whose suitability is measured against the points system. ${ }^{1}$ Admission to Canada for this class has been primarily contingent upon medical, criminal and background screening, as well as proof on the part of the sponsor of the capacity to provide financial support during an initial 10-year sponsorship period (Alternative Planning Group, 2009). ${ }^{2}$ Older immigrants may therefore be less likely to be fluent in one of Canada's official languages; aside from the language challenges there may be a lack of available employment options for older people who do not have Canadian work experience; and adaptation to foreign practices and cultural norms may prove difficult, all factors which can lead to an increased incidence of isolation among this demographic group. As older immigrants face the health-related challenges of the later-life aging process, they may eventually encounter the need for institutional long-term care services. The traditional institutional frameworks for addressing the health care needs of our older population may prove to be incompatible with cultural norms and preferences and further contribute to a

\footnotetext{
${ }^{1}$ As of November 5, 2011, the Government of Canada placed a 24-month temporary pause on further sponsorship of parents and grandparents under the family class due to backlogs in the processing of applications. This forms part of the Action Plan for Faster Family Reunification. At the time of this writing, the future of parent and grandparent sponsorship is unknown, as the federal government will conduct a policy review to determine a way forward (Citizenship and Immigration Canada, 2011).

${ }^{2}$ Under the provisions for sponsorship of parents and grandparents, sponsors have been legally bound to guarantee financial support to their sponsored parents and grandparents during the first ten years of residency in Canada (Alternative Planning Group, 2009).
} 
sense of isolation. The availability of culturally appropriate long-term care at this stage in one's life may greatly reduce the strain of institutional living for older immigrants. Ethnospecific long-term care facilities are designed to address the cultural needs of older immigrants, thereby reducing the stress of institutional living. This research will therefore aim to answer the following research questions: How do ethno-specific long-term care facilities meet the cultural needs of older immigrants, thereby reducing the environmental stress of institutional living? What are the challenges ethno-specific long-term care facilities encounter in their attempts to meet the cultural needs of older immigrants and how do they overcome them?

This research is based on a review of the literature addressing cultural care, ecological models of aging, and older immigrants in long-term care setting, as well as on Key Informant interviews with ethno-specific long-term care facility administrators. In addition, I have drawn on my own experience working in elder care settings. ${ }^{3}$ Having witnessed numerous older immigrants face the challenges of settlement within a residential or institutional setting populated predominantly by Canadian-born seniors, I was interested in gaining an understanding of how long-term care facilities in the Greater Toronto Area (GTA) are addressing the needs of minority populations, particularly as this demographic group continues to grow.

The issue of long-term care for older immigrants is taking on increased importance in Canada. The nation is facing an aging population. Immigration is one of the primary strategies undertaken by the Canadian government to address the declining birth rate among

\footnotetext{
${ }^{3}$ It is important to distinguish between long-term care facilities and what I have termed elder care settings. Long-term care obtains funding from the Ministry of Health and Long-Term Care and is subject to the LongTerm Care Homes Act. Elder care settings represent a variety of care settings, ranging from aging-in-place programs, day programs, to privately funded retirement homes that offer a range of services and nursing care.
} 
the Canadian-born and naturalized Canadian population (Statistics Canada, 2012). As of 2011 , those over the age of 65 accounted for $14.8 \%$ of the population, or approximately 4.9 million, up from 13.7\% in 2006 (Statistics Canada, 2012). This number is expected to grow to 9.9 million by 2036 (Statistics Canada, 2010). The overall immigrant population accounted for approximately $20 \%$ of the population in 2006 ; however, of the $13.7 \%$ of Canadians above the age of 65 in 2006, older immigrants represented $30 \%$ of all seniors in Canada (Alternative Planning Group, 2009). In 2010, parents and grandparents accounted for $5.7 \%$ of all new immigrants coming to Canada (CIC, 2011a). This sets the stage for increased attention being paid to how health care will be provided to older immigrants.

Recent attention has been given to the issue of care models for older immigrants. A Special Senate committee was formed in 2006 to examine the implications of aging in Canadian society. The committee was tasked with addressing a number of specific issues, including, but not limited to, health care needs, home care and caregiving (Special Senate Committee on Aging, 2009). The Special Senate Committee on Aging released its final report in April 2009 entitled "Canada's Aging Population: Seizing the Opportunity". The report points to a number of issues related to care, focusing on how Canadians can address the challenges of an aging population. The committee also focused on care for a culturally diverse population, stating, "The Committee urges the federal government take a proactive role in communicating information and best practices about adapting long-term care facilities to address the needs of multicultural society" (p. 53). Moreover, the province of Ontario recognizes cultural needs as a core element of care; consequently, provisions are in place in the Long-Term Care Homes Act (Ontario, 2010), which include considerations of the cultural, spiritual and religious preferences in resident 
assessment and care plan design. The availability of ethno-specific long-term care can alleviate some of the challenges faced by older immigrants as they face declining health and a decreased level of independence. How this accommodation is being provided in long-term care settings that specialize in culturally sensitive care, namely, ethno-specific facilities, is what will be examined in this research to determine what such "best practices" are.

\section{Definitions}

In order to have a discussion on how the cultural needs of older immigrants are being met within the long-term care setting, it is necessary to establish basic definitions around aging and long-term care. Definitions of ethnicity and considerations of cultural care are addressed in the review of the literature.

Different definitions have emerged to describe what constitutes the terms "older persons" and "aging". As life experiences and even life expectancies differ widely throughout the world, universal definitions of older persons and the aged are somewhat arbitrary. The United Nations currently uses 60 as the cutoff age to refer to older persons (World Health Organization [WHO], 2012b). Canada has historically used the age of 65 to define a person as a senior citizen, at which point they have been eligible for Old Age Security benefits ${ }^{4}$ (Durst, 2005). As this research has been conducted in Canadian institutions, the age of 65 will be utilized to define older persons. However, data collected do not differentiate between those older immigrants who are above or below this threshold, as individualized data on specific clients were not part of the research protocol, and were therefore not gathered.

\footnotetext{
4 Budget 2012 introduced changes to the Old Age Security Act, increasing the age of eligibility from 65 to 67. This will take effect in 2023, which will likely have widespread impacts on definitions of old age in Canada, as well as direct impacts on income security and access to long-term care (Service Canada, 2012).
} 
Long-term care is comprised of a variety of services with varying degrees of care provision. Long-term care has traditionally been associated with institutional living; however, there is an increase in the trend towards providing aging-in-place services, which promote the possibility for older persons to remain in their homes as they age (Barresi \& Stull, 1993; Brotman, 2002), as well as offer entrance into supportive living environments which provide varying degrees of assistance with activities of daily living (Harris, Grootjans $\&$ Wenham, 2008). For the purposes of this paper, however, the focus is on institutional care in long-term care settings, which are commonly referred to as nursing homes.

\section{Theoretical Framework}

I have approached my research by creating a new theoretical framework: An Ecological Model for Culturally Sensitive Care for Older Immigrants. This framework combines two previously established theories of care and aging to examine how the cultural needs and preferences of older immigrants are being addressed in the long-term care sector. I have drawn upon Leininger's theory of cultural care (1988), which outlines critical elements of cultural consideration in nursing care, to set the foundation for analyzing the importance of care as an element of wellbeing among older immigrants. However, this framework was insufficient on its own to examine the how the contextual elements of the long-term care environment contribute to the adjustment and wellbeing of older immigrants. Therefore, I have also drawn upon Lawton's (1977) theory of ecological aging and adaptability to examine how the various policies and programs in ethno-specific long-term care settings contribute to enriching the lives of older immigrants living in institutional care. Lawton's theory takes into consideration the impact of environmental stressors, what is referred to as environmental press, in light of individual internal competencies. As older immigrants face 
declining health, individual competencies may be reduced. This may mean that care intervention is required, at times involving admission into the long-term care system. The presence of culturally familiar practices may serve to alleviate some of the stressors that are common barriers to accessing quality health care (Gelfand, 2003). Language barriers, the absence of culturally familiar practices of health service provision, and a lack of knowledge

of cultural norms have historically contributed to older immigrants' difficulties in navigating the health care system. As conventional long-term care in Canada has taken primarily a dominant cultural approach, tailored to cultural norms and practices of Western society, many older immigrants face challenges within this environment (Disman \& Disman, 1995). The availability of ethno-specific long-term care can alleviate some of the challenges associated with aging for those fortunate to have access to a facility designed for their community.

\section{Leininger's theory of cultural care}

Leininger's theory of cultural care is founded upon the principle that people of different cultures have different expectations and responses to the care they receive from those who provide it. Culturally based frameworks are needed to guide nursing care, as care and culture are inextricably linked and cannot be separated out from nursing care actions and decisions (Leininger, 1988). The theory is used to generate data about diverse aspect of care, including meanings, patterns and experiences, and to gain insight into care in diverse cultures. Leininger (1988) argues that factors such as technology, religion, kinship, cultural values, politics, economics, and education all influence care and health in different environmental contexts and expressions and patterns of care take on different meanings in different cultural contexts. Examples of this which Leininger (1988) gives include the 
marked differences that exist between Western and non-Western cultures regarding care values; technological nursing practices that may increase the distance between the client and the nurse in care relationships; and the ability to interpret care meanings inherent in local language uses.

Leininger's theory outlines a set of eight assumptive premises of care as they relate to cultural needs and beliefs. Two of these assumptions are of particular importance to the examination of long-term care service provision to older immigrants:

1 - Knowledge of meanings and practices derived from worldviews, social structure factors, cultural values, environmental context, and language uses are essential to guide nursing decisions and actions in providing culturally congruent care.

2 - Cultures have folk and professional care values, beliefs, and practices that influence cultural care practices in Western and non-Western cultures (Leininger, 1988).

The integration of these elements into the practices within ethno-specific long-term care can help diminish the adverse health and mental health consequences resulting from the lack of cultural congruence present in mainstream long-term care settings (Kahana, Kahana, Sterin, Fedirko \& Taylor, 1993).

\section{Lawton's ecological model of aging and adaptability}

Lawton's ecological model of aging and adaptability is based upon the premise that, within all people, there exists a balance between individual competence and environmental press. According to Lawton, competence is categorized as the abilities within persons based on their level of functioning. A lowered competence may result from challenges such as cognitive impairments, age-related sensory loss, or physical impairments. Environmental 
press -commonly referred to as stressors - represents the aspects of the environment that have a potential demand element on the competence of a person (Lawton, 1977). Press factors on their own are neutral. It is only when the individual competence level is compromised or augmented that there is a value of negative or positive demand attached to it. They can include basic elements such as the one Lawton cites, which is heating fuel in one's house. It is only when gaining access to heating fuel is beyond the physical capacity of the person that it becomes a negative press (Lawton, 1977). Lawton (1977) argues that those with very limited abilities to perform everyday tasks of living, such as those requiring longterm care services for food and personal care, are a group for whom even relatively small degrees of environmental pressure from their environment may negatively impact their wellbeing.

For older immigrants, the environmental stress associated with institutional living, when exacerbated by foreign cultural care practices, language barriers, and isolation from culturally familiar markers, can increase, contributing to the double-jeopardy hypothesis identified by Dowd and Bengtson in 1978. This double-jeopardy hypothesis holds that, in addition to the disadvantage experienced through their ethnic minority status, older immigrants also experience the devaluation in status associated with old age (Coon, 1986; Dowd \& Bengtson, 1978). The presence of culturally familiar supports, such as traditional health practices and fellow native language speakers, as well as supportive social networks can alleviate the negative impact of the environmental stressors. 


\section{A New Theoretical Approach: An Ecological Model for Culturally Sensitive Care for Older Immigrants}

To research this alleviation adequately and identify the best practices that provide it, Leininger's and Lawton's theoretical frameworks must be combined to create what I have called An Ecological Model for Culturally Sensitive Care for Older Immigrants. Specifically, this theory holds that the provision of culturally appropriate care in ethno-specific long-term care settings can alleviate certain environmental stress factors associated with institutional living, aging and immigration.

This research will therefore address the following questions: How do ethno-specific long-term care facilities meet the cultural needs of older immigrants, thereby reducing the environmental stress of institutional living? What are the challenges ethno-specific long-term care facilities encounter in their attempts to meet the cultural needs of older immigrants and how do they overcome them? To address these questions, I have used qualitative research techniques involving interviews with Key Informants who are at the administrator and senior management level in seven ethno-specific long-term care facilities. The aim of the interviews was to gather data on the practices in place in various ethno-specific long-term care facilities that specifically address the cultural needs of immigrant residents, and prevent the disconnect between the needs of older immigrants and the long-term care sector. This will be done based on the new, combined theoretical framework discussed above in order to address the gap in the literature reflecting an ecological model for cultural care and adaptability. 


\section{REVIEW OF THE LITERATURE}

The literature to date on aging, ethnicity and health care has been focused primarily around the burden of care on family caregivers (Brotman, 2002); barriers to accessing primary health care (Brotman, 2002; Deri, 2005; Lai, 2004; Wu \& Hart, 2002) and the social determinants of health for older immigrants (Deri, 2005; Dunn \& Dyck, 2000; Lai, 2004). As well, several studies have examined how cultural norms have influenced the living arrangements of older immigrants, and the decision-making process for residential care versus aging in place (Baker, Benjamin \& Fan, 2009; Brotman, 2002; Kaida, Moyser \& Park, 2009; Treas \& Mazumdar, 2002). A select number of authors has addressed the institutional long-term care setting, and how older immigrants adjust to these environments (Brotman, 2003; Kahana et al., 1993; Kaplan \& Shore, 1993). Kahana et al. (1993) argue that personal characteristics related to ethnicity, such as acculturation, locus of control, and cultural congruence with the environment, predict morale for immigrant elderly in long-term care. Kaplan and Shore (1993) have looked specifically at how Jewish communities have addressed long-term care in the United

Sates, drawing on the innovation of services within Jewish communities and evolution of Jewish aid societies to examine best practices. Brotman (2003) draws attention to the power relations and inherent racism in the institutional structures of long-term care to argue that multiculturalism programming, in its current form within mainstream longterm care, fails to sufficiently address the systemic causes of racism towards residents.

The aging of Canada's population brings about an increased reliance on the health care system. High numbers of aging and older immigrants in Canada support the need for future research examining how health care, and specifically, institutional long-term care 
settings, are being designed to meet the various health-related needs of older immigrants, while providing culturally relevant care. As previously discussed, Canada's population is aging, with the first of the baby-boomer generation reaching the age of 65 in 2011 (Statistics Canada, 2012). Current projections indicate that the number of seniors relative to the rest of the population could double over the next 25 years, should fertility rates remain unchanged (Statistics Canada, 2012). Of the $13.7 \%$ of the population over the age of $65,30 \%$ of these are immigrants (Alternative Planning Group, 2009).

Historically, immigration to Canada was primarily fueled by European migrants, where cultural traditions, health care practices, and ideas around aging mirror to at least some extent the dominant practices in Canada. In 1967, Canada's immigration policy changed from primarily ethnicity-based criteria, which favoured European migrants over others, to the points system (Green, 2004). This removed ethnicity as a selection criterion for immigration and gave applicants a score based on the likelihood of the applicant to be able to settle successfully in Canada ${ }^{5}$ (Kelley and Trebilcock, 2010). This shift in policy has resulted in a shift in primary source countries of immigrants, moving from the traditional European base to an increasing number of immigrants from Asia, South East Asia and Africa (Statistics Canada, 2007; Green, 2004). In 2006, 58.3\% of immigrants to Canada came from Asia, whereas newcomers born in Europe made up only $16.1 \%$ of all recent immigrants (Statistics Canada, 2007). In comparison, in 1962, 78\% of all immigrants came from Europe, whereas immigrants coming from Asia and the Caribbean accounted for only 10\% in 1965-6 (Kelley \& Trebilcock, 2011). The change in source

\footnotetext{
${ }^{5}$ Applicants scores were based on the following categories: age, education, training, occupational skill in demand, knowledge of one of Canada's official language, a personal assessment made by an immigration official in an interview, relatives in Canada, arranged employment and employment opportunities in the area of destination.
} 
countries has led to a shift in thinking about how health care services are delivered and how an adaptation from cultural norms of the dominant group can accommodate the practices of newcomers. Long-term care services to meet the needs of such a diverse population have not kept pace, however, creating a now-pressing need for more ethnosensitive models for institutional care.

The availability of ethno-specific care has been lacking in part due to the cultural preference for how elder care is delivered among certain groups of immigrants (Brotman, 2003; Chappell, 2003; Disman \& Disman, 1995). Within a number of ethnic groups whose representation in Canada has been increasing in recent years, institutionalization has not been common practice. As Lai (2002) points out, older Chinese immigrants, who comprise approximately $11 \%$ of the Chinese Canadian population (Chau \& Lai, 2011), have traditionally relied on their grown children and extended family to provide care into older age. Mausbach et al. (2004) argue that Latina caregivers are much less likely to institutionalize their elder family members when compared to Caucasians in the United States, and delay institutionalization upon the onset of dementia far longer than their Caucasian counterparts. Cultural values, as well as the positive view towards the role of caregiver were argued to be possible reasons for the delay in institutionalization.

A combination of factors has led to a growing shift among diverse populations to consider institutional living as an option for elder care. As immigrants settle in Canada, some may shed traditional cultural practices in favour of Western norms. This has been widely documented in the literature on social isolation facing older immigrants as they migrate to Canada to join their children and grandchildren, only to express misgivings towards migration due to the changing cultural practices within their extended families 
(Brotman, 2002; Lee, 2004). Even amongst certain Eastern and Southern European groups who comprised some of Canada's earlier immigrants, such as Italians and Portuguese migrating to Canada prior to the introduction of the points system, and where cultural tradition historically dictated that grown children and extended family networks assume the role of caregiver, institutional care has become a more acceptable practice, both in Canada and in the country of origin (Wister, Pereira \& Lazarowich, 1996). As well, there is a growing body of literature that suggests the argument that ethnic minorities will "take care of their own" is increasingly on the decline (Chappell, 2003; Lee, 2004; Wright \& Mindel, 1993), and as such, it should not be assumed that ethnic elders will not require specific targeted services to meet their needs.

Prior to a discussion on the role of ethnicity related to the provision of services to older immigrants, it is necessary to first establish what is meant by the term ethnicity, and consequently, ethno-specific long-term care. Gelfand (2003) draws on three main components to describe ethnicity: (1) the identification of the group as an ethnic or racial group by others, (2) the identification of the group as ethnic or racial by the group members themselves, and (3) specific behaviour patterns that distinguish the group. Holzberg (1982) proposes a more detailed consideration of ethnicity to comprise, ...social differentiation based on such cultural criteria as a sense of peoplehood, shared history, a common place of origin, language, dress and free preferences, and participation in particular clubs or voluntary associations, engenders a sense of exclusiveness and self-awareness that one is a member of a distinct and bounded social group. But it is not the ethnic content (markers) per se that constitutes the diacritica of social 
differentiation. More important for the purposes of social distance are the feelings of shared particularity, self-identification, and membership in ethnic-exclusive associations. (Holzberg, 1982, p. 252, as cited in Gelfand, 2003, p. 5).

Ethnicity can therefore serve as a powerful element in the creation and maintenance of bonds within a group. It has been well documented that ethnic ties can serve as major influences in shaping the social world and social experiences of older adults (Andersen \& Newman, 1973; Gelfand \& Kutzik, 1979). Ethnicity, it has been argued, can work as a possible buffer against a number of negative aspects of aging (Gelfand, 2003; Wister et al., 1996), particularly through activity in ethnically related social welfare organizations, religious organizations and/or ethnic cultural organizations (Gelfand, 2003).

As immigrants age and experience the isolative effects of declining health, distance from familiar cultural practices, the presence of culturally familiar elements can alleviate the challenges of cross-cultural nursing (Jones \& van Amelsvoort Jones, 1986; Leininger 1988). As noted above, the long-term care setting itself can act as a significant stressor to older persons, through the loss of previous familiar surroundings, independence, and the demands and restrictions associated with institutional living (Kahana et al., 1993). As Chau and Lei (2011) argue, during times of transition it is natural for ethno-cultural minorities to look towards other members of their ethnocultural group for support. These support systems can provide stability and encourage individual and personal growth by guiding behaviours according to culturally based values and beliefs, while rebuilding the loss of community experienced when relocating to an institutional environment. The creation of ethno-specific long-term care facilities, 
with targeted programs aimed at meeting the cultural needs of older immigrants, can alleviate some of the stress factors of aging and declining health. The determination of what constitutes an ethno-specific long-term care facility would therefore reflect the elements described above: one that provides appropriate services and care to at least one specific ethno-cultural group of residents in a culturally sensitive manner.

The role of ethnicity is a critical issue when considering how services are provided to older immigrants. Ethnicity plays a significant role in shaping the lifestyles and defining service needs of older immigrants (Abramson, 1980; Bengtson, 1979). As Kahana et al. (1993) argue, the concept of the melting pot that the United States has adopted has not homogenized elderly of diverse cultural and ethnic origins. Canada has not subscribed to the melting pot approach of the United States, but rather, with the passing of the Canadian Multiculturalism Act (1988), Canada's official policy on multiculturalism is to "... recognize and promote the understanding that multiculturalism reflects the cultural and racial diversity of Canadian society and acknowledges the freedom of all members of Canadian society to preserve, enhance and share their cultural heritage" (Canadian Multiculturalism Act, 1988). Therefore, the maintenance of ethnospecific practices and cultural traditions has been enshrined in Canadian policies and practices, creating the opportunity for cultural continuity. However, as Brotman (2003) argues, the considerations of multiculturalism in long-term care have been insufficient to address the institutionalized racism and power relations inherent in the system.

\section{Cultural care}

The discourse on cultural care for immigrants has been growing in recent years; however, much of the focus has been on service provision within the general health care 
sector that addresses cultural preferences in how care is delivered, as well as the barriers faced by immigrants in navigating services within the Canadian health care system (Lai, $2005 ; 2007)$. As previously discussed, while attention has been paid to issues surrounding older immigrants and their overall health indicators, much of the focus has been placed on mental health aspects related to isolation within the community, the stress of familial expectations and responsibility, the loss of independence post-migration, and the strain experienced by family caregivers who are charged with providing care to older immigrant family members (Lai, 2007). Few have looked at the impact of institutional living on older immigrants and the challenges associated with accessing ethno-specific services.

The strain associated with relocation to an institutional long-term care setting can be exacerbated by unfamiliar cultural practices. For many older immigrants who had previously been residing with their adult children and/or spouse, the loss of support from their former caregiver can be alienating and confusing, and may increase the incidence of isolation associated with institutional living and cultural mismatch (Brotman, 2003). Often the primary caregiver has not only provided nursing and personal care, but has also served as translator and facilitator of care when language barriers and cognitive functioning have served as an impediment to accessing care (Lai, 2007; Treas \& Mazumdar, 2002). As previously mentioned, traditional long-term care residences in Canada have taken a dominant culture approach, which fails to take into account the cultural needs of the diverse population, creating what can be an hostile environment for older immigrants belonging to ethnic minority groups; they thus ignore the loss of culture and community encountered with both the aging and immigration process (Disman \& Disman, 1995). Although the presence of culturally appropriate care does not necessarily 
negate the impacts of institutional living and relocation for older immigrants, it may serve as a useful mechanism in better meeting the cultural needs of this demographic group.

Several authors have examined how different cultures negotiate their personal care needs and those of their family members in keeping with traditional practices. Divergent themes have been highlighted, such as the importance of family and kinship ties in care practice (Lundberg, 2000); the role that religious and spiritual beliefs play in care and perceptions of health (Emami, Benner \& Ekman, 2001; Lundberg, 2000); the impact of language barriers on the quality of care received (Jones \& van Amelsvoort Jones, 1986); and the importance of maintaining traditional health practices and treatments (Emami et al., 2001; Lundberg, 2000). As Kaplan \& Shore (1993) explain, the proliferation of ethnic or culturally-specific long-term care facilities has been motivated by religious, national or other culturally-based concerns to provide an environment whereby the aged could share their heritage, celebrate their holidays, worship without fear or ridicule, enjoy special foods, and feel understood, wanted, protected and nurtured. These elements are often overlooked within mainstream long-term care, resulting in what Rowles (1980) describes as a deprivation of one's sense of "autobiographical insideness" found in community and cultural connections. As Gerrish, Husband and MacKenzie (1996) discuss,

Food...while a basic human need, is the vehicle for a ritual and meaning across the range of cultural mores... Yet such a basic shared need is apparently one of the most frequent signs for ethnocentric thoughtlessness. Failure...to meet the dietary expectations of minority ethnic clients ranges from total non-recognition of their distinctive cultural expectations to a 
serious-minded recognition of this as an issue in cross-cultural care, which is then confounded by a narrow stereotypical definition of 'what they eat'. (p. 122).

The presence of culturally sensitive care models in long-term care work to address these gaps, promoting the delivery of care and services that meet the cultural, spiritual, and personal needs of older immigrants.

\section{Lawton's ecological model of aging and adaptability}

There has been an increased focus on the importance of setting and environment in various contexts of service provision aimed at health promotion (Harris et al., 2008). Harris's and Grootjans' (2006) analysis of the role of ecological health approaches and their potential for promoting healthy aging underscores the increased acceptance of environmental press factors as contributing to the overall determinants of health in aging. Through the utility of a settings approach, ecological health promotion is operationalized to emphasize the role that place and environment play in creating and promoting health, based on the physical environments in which people engage. With the recognition that many determinants of health are social or environmental in nature, and not within the direct control of the individual, setting-based approaches examine the place of people in a wider socioecological system, recognizing the resulting impact on health (Green, Poland \& Rootman, 2000; Harris et al., 2008). The World Health Organization (WHO) has endorsed a settings approach to health promotion, taking into consideration the whole system or organization as the context for promoting healthy lifestyles (WHO, 2012a), and recognizes that healthy settings within institutions can improve health indicators (WHO, 2012a). This echoes Lawton's ecological model of aging and adaptability, and the 
understanding of what Harris et al. (2008) describe as a complex interaction between the individual and society, where the health and wellbeing of the individual are dependent on the interaction of the two.

Kahana et al. (1993) utilize Lawton's theory to examine the importance of culturally congruent environmental settings for adaptation among the institutionalized ethnic elderly. Specifically, they use Lawton's (1973) environmental docility hypothesis, which suggests the more competent the person is, the less dependent that person is on environmental circumstances, to illustrate how the ethnic elderly with more limited social resources and coping skills are more severely impacted by the institutionalization process than those who had greater degrees of socially supportive community around them. This reinforces the double-jeopardy hypothesis for the ethnic elderly, with the findings suggesting the ethnic elderly are more likely to be at a disadvantage within institutional settings due to the challenges of aging as well as immigration (Dowd \& Bengtson, 1978).

The ecological model of aging and adaptability provides a crucial lens through which to interpret the importance of culturally appropriate care provision within the longterm care setting. The linkages between environmental stress factors and human response contribute greatly to the discourse on ethno-specific care that can serve to reduce the environmental press experienced by older immigrants. Doing so in a culturally appropriate manner that meets the needs of older immigrants may greatly enhance their wellbeing and adjustment to the challenges of later-life migration, declining health, and institutional living. In order to adequately address this challenge, however, it is necessary to look at how cultural care, as outlined by Leininger (1988), alleviates the environmental stress of institutional living, reducing the burden on individual competence argued by 
Lawton (1977). This can assist in better addressing how cultural care frameworks are designed and implemented. The following research, combining the theoretical insights of Leininger and Lawton, aims to address this gap in our knowledge. 


\section{METHODOLOGY}

The previous chapter examined concepts of cultural care and the ecological model of aging and adaptability as they relate to ethno-specific long-term care settings. The remainder of this paper seeks to explore ethno-specific care delivery to older immigrants in the GTA through the lens of a new ecological model for cultural care and adaptability. More specifically, the objective is to gather data on what the challenges and best practices are for the delivery of a holistic approach to culturally appropriate care in ethnospecific long-term care facilities. This research was designed to answer the following questions: How are ethno-specific long-term care facilities addressing the cultural needs of their residents? What are the challenges to be overcome and best practices to be followed in meeting those cultural needs? The responses to these questions will form the basis for a template of culturally appropriate care provision. This chapter will first outline the method through which data were collected. I then provide a description of the analytical template created to demonstrate best practices and lessons learned through the framework created. Secondly, I have presented a rationale for selecting a qualitative approach to the study versus a quantitative approach. Thirdly, I address some of the limitations of the research design. Finally, I outline the method for coding of data that formed the basis of the themes identified in the findings.

\section{Methodological Approach}

There are two main methodological options when conducting empirical research: qualitative and quantitative. Quantitative studies are suitable when theories are being applied to data to deduce patterns among predefined variables. In contrast, qualitative 
design allows for a more inductive approach, with themes and explanations emerging from the data (Wesley, 2011). As my research questions aim to uncover the cultural elements that ethno-specific facilities consider critical to older immigrants in long-term care settings, I have chosen to utilize qualitative methods. It was important for the research to be amenable to an open flowing discussion with participants that would allow primary themes to emerge from the data, rather than reflecting a pre-determined set of variables and criteria, as the importance of cultural elements vary across the spectrum of ethnic settings. In order to achieve this, I utilized the evaluations, judgments and opinions of senior practitioners in the long-term care sector to uncover how culturally appropriate care is being delivered.

\section{Participant recruitment and research design}

Participants were recruited through the use of purposive sampling, as the aim of the research was to solicit responses from a select group of experts in the field of ethnospecific long-term care. Potential participants were identified through a variety of sources. These included use of pre-established contacts within the long-term care sector in the GTA. As well, further participants were identified and recruited through the use of the Toronto Regional Community Care Access Centre listing of long-term care facilities, which identifies those facilities that are ethno-specific in nature and provide culturally appropriate care. Snowball sampling, although not an initial part of the research design, was later involved in the recruitment process, as participants offered to refer my research to other colleagues within their long-term care networks.

Data were collected through the use of seven Key Informant interviews. Initially, I had intended to complete at minimum of eight interviews; however, because of 
difficulties I encountered in recruiting participants, as well as one participant withdrawing from the study late in the process, only seven interviews are included in the findings. The Key Informants were well positioned to provide insight into how culturally appropriate care is being delivered, as they have been involved in the design and implementation of these elements of the care regime. Moreover, they interact on a daily basis with the population being served, as well as with family members who often act as advocates for their aging relatives in care. The questions posed to Key Informants are available in Appendix A.

The data were collected based on semi-structured interview questions designed to address a number of key components of importance in providing culturally appropriate care. These elements were drawn from both the researcher's personal experience in the long-term care sector, as well as from the literature on cultural care and ecological aging and adaptability. The questions included inquiry into five main areas of the service provision within each facility, which are: dietary practices; language practices; religious observances; activity programming; and nursing care practices. Participants were asked to provide information on whether these services were being provided in a culturally specific manner for their target population and the effect this had on their residents, as well as to identify the main challenges staff face in delivery of culturally appropriate care. In addition, participants were asked about their facility's official policy on providing culturally appropriate care with the goal of contributing to a common definition of culturally appropriate care. Finally, participants were asked to identify any additional cultural elements requested for accommodation, and barriers, challenges and opportunities for doing so. 


\section{Analytical Template}

Data collected from this study were coded and categorized based on a template created to reflect elements of the ecological model for culturally sensitive care for older immigrants utilized. In order to situate the findings into a product of utility for ethnospecific long-term care, part of the aim of the research design was to create a template of the best practices and lessons learned, based on the elements of environmental stress and individual competencies drawn from Lawton's (1977) theory, which would also incorporate the importance of the elements defined by Leininger's (1988) theory of

cultural care. The template is available in Appendix B. The research questions were designed to promote a discussion that would allow themes of cultural care to emerge in how each element of environmental stress and individual competence was affected by the provision of culturally appropriate care. It is hoped that this template serves as a useful tool in the planning and implementation of ethno-specific long-term care practices within the industry.

\section{Coding}

General themes and concepts about how culturally appropriate care is being delivered to older immigrants were gleaned from both the literature and the Key Informant interviews during the open coding process. During the axial coding stage, I then was able to tag the various themes into broad categories of analysis that reflected the experiences in providing culturally appropriate care, as well as reflecting on my own experience within the long-term care sector. Finally, I further streamlined the themes and 
categories during the selective coding process in order to create a clear and concise perspective of how themes interact. 


\section{FINDINGS}

Through conducting Key Informant interviews with seven senior level administrators of long-term care facilities that cater to ethno-specific needs, a number of key themes emerged that highlighted the importance that culturally appropriate care has on the wellbeing of older immigrants in institutional care settings. Because of the breadth of information received during the interview process, as well as the aim of the research design, I have divided the findings into two main categories. The first deals with successes of ethno-specific long-term care in addressing the cultural needs of residents, which fall under the heading of Best Practices. The second section will address the challenges to engaging in such best practices. These are discussed under the Lessons Learned. As long-term care caters to people in declining health who are experiencing some of the more extreme challenges of aging, no program or solution can alleviate all challenges. Many of the themes presented in the best practices are therefore also echoed in the lessons learned.

\section{Best Practices}

\section{Ease of Interaction}

I have grouped responses regarding language acquisition, language barriers, and efforts to mitigate language-based barriers under the heading of ease of interaction. As with much of the literature on immigration and challenges to settlement and integration, language emerged as the primary challenge within ethno-specific long-term care. Moreover, a common issue that emerged was the effects of dementia on language and communication. All seven respondents indicated that they experience challenges 
associated with dementia and its impact upon communication, as residents often revert to their mother tongue as dementia progresses, losing any functioning they may have once had in English. How each facility addresses this challenge in order to meet the care needs of their older immigrant population is discussed below.

Six of the seven respondents indicated they had made efforts to recruit staff who spoke the principal languages of their residents. The one exception did not indicate a specific recruitment strategy in this area; however, through their connection to the community, the large pool of volunteers of similar ethnic background, as well as nativelanguage-speaking staff employed at the facility, it has not proven to be as significant an issue. All seven participants indicated that they used a variety of ad-hoc coping and translation strategies, such as relying on staff who speak a language or dialect close to that of the resident to translate; asking family members to assist with translation, when available; calling upon family members to assist in translation for other residents in cases of emergency, and ensuring that a staff member or community volunteer who speaks the resident's native language be present during care planning meetings.

Language barriers in a nursing environment can not only lead to isolation for the resident, but perhaps more seriously, misdiagnosis or staff being unaware that a resident is in distress. Therefore, in this environment, language becomes not only an issue of cultural connection, but also one of health and welfare. The strategies in place to address this challenge varied greatly by residence. Four administrators indicated that enabling technologies had been introduced to assist in translation. One residence in particular had introduced a pictographic computer with voice translation set to specific languages. Residents are able to choose an image that depicts what they are feeling, with the 
computer then stating it in their language first for them to confirm, followed by providing the English translation to the nursing staff. Three other administrators indicated using word boards, cue cards, or internet-based translation programs in order to communicate with their residents when direct person-to-person translation was not available. It was also noted by three administrators that, despite not always being able to find staff who are fluent in the native language of their residents, over time many staff members were able to pick up the language spoken by the residents. As well, one facility is looking into the possibility of providing language training to the staff as a means of meeting the demand for native language speakers who are largely absent in the current pool of health care workers.

It became evident that the ability to communicate, specifically with regard to overcoming language barriers, has an overwhelming impact on the quality of life residents face in long-term care, and reduced greatly the environmental stress on residents. The following example was provided by one respondent regarding language and the importance of having native-language-speaking staff:

....as we age, we lose a lot of the learned, acquired habits and language..., so they revert to their mother tongue with dementia. And so it's very difficult for them to continue to live in a strange and foreign environment where they feel comfortable [and where] anxiety is reduced...once you speak the language, they immediately calm down...three years ago, we had a resident move in. She had been in another long-term care setting, and the first day [she was here], her daughter said, “I didn't know my mother could still talk!" because our staff to her in Shanghainese [her 
mother tongue]. In three years in another long-term care setting, she never said one word [as Shanghainese was not spoken in the previous long-term care setting]. She came in here, the first day she answered. They had no idea she could still talk. (personal communication, August 17, 2012). Reducing the stress on individual competencies through language was identified as a critical element to settlement in the long-term care setting. It has the potential to alleviate a sense of isolation and improve quality of life. Having that capacity within each ethnospecific long-term care setting has proven to be a challenge, as the supply of trained nursing staff specific to each ethnic community is not always high. The use of volunteers from the community therefore was a predominant theme in the participants' responses. Four of the seven facilities in the study indicated that community volunteers are often utilized to serve as translators, provide for cultural connections, and reduce isolation. As one administrator noted,

We had one resident who constantly screamed all the time. She wasn't screaming though, that was her only way of communication. And she liked people to read to her but only in her language. And staff were not able to do that. They barely have enough time to get their own work done. So we got a volunteer to come in every day to read to her and within four to six weeks, her screaming slowly started declining because here now she was getting what she needed; she needed someone to communicate with her, so that was her way of communicating. We didn't understand she couldn't make herself understood because of her dementia but meeting her needs of having someone like a friendly [visitor] and having someone read 
to her, we were actually able to manage her behaviours. Because we couldn't have her in the dining room, she was so disruptive that all the other residents would stop eating so she was isolated to her room because we had no other choice. (personal communication, July 31, 2012).

In order to better meet the needs of the specific ethnic group of each facility, all seven respondents indicated their monthly activity calendar is translated into the principal ethnic group's native language. As well, four of the seven indicated holding resident council meetings and family council meetings in both English and the native language of the principal group, in order to allow full participation from as many residents as possible. Six of the seven respondents indicated that activity programs within their facility are, at least on occasion, conducted in the language of their principal ethnic group.

\section{Cultural norms}

I have grouped responses that reflected addressing of cultural needs of the residents under the heading of cultural norms. This is a rather broad category, with elements that could apply to a number of other categories, as culture is salient to most issues of settlement into long-term care and the manner in which these are manifested. I have therefore divided the findings into a number of sub-categories. They are as follows: continuity of cultural norms; spiritual continuity; cultural understanding and preference.

\section{Continuity of cultural norms}

Cultural norms are at the core of providing cultural care. Therefore, they permeate every aspect of residential care, from nursing practices to dietary needs to religious 
observances, and beyond. They are integrated into all aspects of ethno-specific care; if language provides the avenue for expressing one's needs, it can be argued that cultural norms provide the content of those needs.

One of the biggest challenges facing long-term care administrators is meeting the dietary requests of all residents. This was evident during my own experience working in longterm care, and was only reinforced through my research. Food plays an important part in providing some form of cultural familiarity; however, it is often not purely a means of sustenance; often it also signifies a critical element of tradition and ritual. As Gerrish et al. (1996) had discussed, the provision of culturally familiar foods is often overlooked in mainstream long-term care. All participants indicated the availability of culturally familiar foods as a primary concern and priority for their residents. All seven residences indicated that they do accommodate dietary requests for ethnically familiar foods, although the ability to do so varied by residence due to the funding structure ${ }^{6}$ of each home and the need to accommodate a variety of ethnicities within one residence. The challenges with providing culturally familiar foods will be dealt with in the following section.

Four residences indicated that they provide a "western" option at all meals, as well as a second option for the principal ethnic group. Two of the residences provide only culturally familiar menus to their residents. In one case, religious practices of the ethnic group required a diet that met certain standards and practices; however, there were provisions in place for accommodating those who did not follow the religious dietary

\footnotetext{
${ }^{6}$ There exists a mixed funding structure within long-term care. As an industry that is a mix of public and private partnerships, there have historically been three categories: nursing homes, municipal homes for the aged and charitable homes for the aged. Funding for each category has been streamlined; however, charitable homes for the aged run on a non-profit structure, which allows them to seek charitable donations to supplement government funding. (Ministry of Health and Long-Term Care, 1999).
} 
practices. The second residence was able to provide only culturally familiar foods, as they had only two main ethnic groups in residence; therefore the demand for a western option did not exist. The administrator from a third residence indicated that they were not able at that time to provide culturally-specific foods to one group, as the proportion of residents who identified as part of the largest ethnic group within the residence only accounted for approximately $50 \%$ of the population of the residence. Therefore, catering to one group in particular was not feasible; however, there have been other efforts to meet the traditional dietary practices of the principal group within the residence, including having a "residents' choice" meal once a week that caters to what the demand is at that time.

All seven of the residences have strong recreational programs in place that are geared towards providing culturally familiar activities for their residents. All reported celebrating both Canadian holidays and holidays that are culturally specific, incorporating elements of traditional practices within their programs. Five of these also had targeted television programming, either streaming channels from their home country through cable access or providing films and special viewing activities that were geared towards the target ethnicity. Celebrations were often marked with entertainment being provided by cultural community groups and performers in all seven residences.

Culturally specific recreational programming extended to a variety of other activities in the various residences. A common theme, which all respondents indicated, was their activity programs, which incorporate cultural elements to their programming. These include exercises, entertainment and celebrations in the facility, group outings, and other recreational events. For Chinese residents, having Tai Chi programs, regular games 
that were culturally familiar, such as Mahjong, and activities such as karaoke nights were seen as critical to providing cultural care. One administrator described a specific program in place for Chinese residents,

...we also have a specific one that's called silent painting. It's a therapy actually, and it's quite great. There's only six allowed at a time....and what they do is they have one picture they're all trying to copy. But it's all in silence; nobody is allowed to speak. And apparently ... back home in China, ... a common thing that people like to do. They gather, it's quiet, it's to meditate and express yourself. (personal communication, July 25, 2012).

Another administrator highlighted how programming within their facility was designed to follow Montessori practices in order to ensure programs are both culturally appropriate as well as geared towards the capabilities of the population in long-term care:

You really have to cater to the interests, because the basis [of Montessori] is that through repetition, through experiential continued working, the resident can actually gain that skill. So you need to engage them in activities that they can identify with. So we have developed themes along Montessori for residents with dementia, and the themes we have come up with include taking care of baby, because for mothers and grandmothers that is something they can readily identify with. We also have a theme around Chinese traditional wedding...they can identify with that...Because I know in another home, their themes are totally different, like sports, cinema, etc. But for Chinese, they wouldn't connect to 
baseball or hockey. They've probably never seen baseball or hockey. So

you have to have themes they can relate to. (personal communication,

August 17, 2012).

\section{Spiritual continuity}

For many older immigrants, spiritual and religious observance plays an important part in their day-to-day lives. Religion continues to be important for many new immigrants (Yang \& Ebaugh, 2001). Maintaining religious connections provides a social space for preserving cultural traditions and ethnic boundaries (Yang \& Ebaugh, 2001). As such, religious observance is a core element of providing culturally appropriate care. Each of the seven administrators interviewed indicated the residence holds religious services catered by the various religions of their principal ethnic group. Moreover, two of the respondents indicated their facility had pastoral care on staff, responsible for tailoring programs and services to fit the needs of their residents, and conducting outreach on behalf of residents who were not of the principal faiths. The remaining five indicated they had close links with pastoral services within the community, maintaining regular religious services and pastoral care for those in need.

Spiritual needs are often intertwined with many other aspects of one's life and are not met solely by attending services or engaging in worship on a weekly basis. Spiritual growth can be integrated into everyday activities. Therefore, a number of activities of daily living must incorporate observance of religious and spiritual practices. Two divergent responses were provided by administrators at three separate facilities regarding how this is addressed. In the first case, the staff was primarily of the same ethnic background as the clientele, and therefore were able to address the spiritual needs with 
ease. As the administrator noted, "There isn't a lot of times we need to explain cultural or spiritual nuances. A lot of that is assumed. We don't need to explain to each other where that belief comes from. We just take it for granted." (personal communication, August 17, 2012). Conversely, another administrator in a facility where staff was predominantly of other ethnicities stated that some of the practices that are spiritual in nature have to be explained to staff, in particular related to showering and dressing. "How they have their baths or showers, you know, they don't want to be exposed of their whole body, you know, one body part at a time, as this is part of their religion." (personal communication, July 31, 2012). Moreover, another administrator recalled encountering residents of Muslim faith, who were not to be touched by females, particularly when nude. This creates challenges for meeting the personal care needs of residents, as staff in health care service provision is predominantly female. However, the administrator indicated that they have increasingly been seeking out male staff who can address this need.

\section{Cultural understanding and preference}

All seven participants indicated that their facilities conduct a thorough intake interview, where care plans are designed to fit the preferences of the resident. During this interview, and on an annual basis, residents' needs and preferences are documented. As mentioned above, it is not only a religious preference, but also a cultural element to not wish to be given personal care by someone of the opposite sex. Three administrators highlighted this issue, and have engaged in efforts to recruit staff of both genders in order to meet the preferences of their residents.

Cultural understanding also involves the sharing back and forth between staff and residents of cultural traditions. Three of the administrators interviewed indicated that 
cultural sharing was a part of their care plans, as well as the professional development for staff. In one facility, a culture day was introduced, where both staff and residents were encouraged to participate, displaying cultural symbols, with staff conducting cultural performances that reflected their native cultures. As well, one residence has an extensive training program for all incoming staff, and has a cultural heritage department that is used as a resource for challenges staff face in understanding the particular cultural nuances of the residents.

\section{Community}

The loss of community, both through the immigration process as well as upon placement in a long-term care facility, was a dominant theme in the interviews conducted. Recreating a sense of community within the facility and maintaining ties to the ethnic community outside the facility were therefore a critical element of the functioning of all seven facilities in the study.

All seven facilities indicated that the presence of ethno-specific long-term care, where people with similar backgrounds live, created a sense of community that was critical to the wellbeing of their residents. Respondents indicated that both through the links made between residents as well as between residents and staff of similar ethnic background, the residence provided residents with a sense of community that might be lacking in non-ethno-specific residences. One respondent recounted how old community ties are sometimes rekindled, as residents discover neighbours from their home country. One respondent indicated that at times, residents will discover that someone from their hometown who speaks the same dialect has moved in and befriend the person; immediately, isolation is reduced, along with depression associated with isolation, and 
often the person then becomes more active and engaged, making them better able to face environmental stressors. As well, as people age, the death of family members can create greater degrees of isolation. As one administrator attested,

A lot of our immigrants, their siblings have died, their parents have died, if they didn't have children, they may have nobody else here. They don't have anyone really, especially as they age, and some of them lose their second language, so they're lonely and that's why these [international exchange students from their home country who are completing placement requirements] are so wonderful. (personal communication, August 16, 2012).

Three of the facilities that had mixed ethnic populations indicated they had created ethno-specific units, in order to ensure residents from the same cultural background were living in close proximity to one another. This can foster a greater sense of community and reinforce the culturally familiar elements that ease the integration process into institutional care.

Reliance on community services from ethno-specific groups was identified as a significant contributor to wellbeing. The maintenance of ties to one's community eases the transition into long-term care, allowing residents to keep one foot in the community, while getting the care they require. As indicated earlier, four of the seven respondents indicated relying heavily on volunteers from within the community to ensure community ties remain a critical element of residents' lives. 


\section{Lessons Learned}

Throughout all discussions with administrators of ethno-specific long-term care, a number of common challenges were identified. After careful analysis, I have divided up the challenges into the following sub-categories: systemic issues; cultural disconnect; and inter/intra-ethnic conflict. Finally, although it is not a cultural element, it is important to acknowledge and understand the challenges associated with declining health for older immigrants, in particular the effects of dementia.

\section{Systemic issues}

Systemic challenges within long-term care contributed to the inability of certain facilities to fully achieve the degree of cultural care desired. A common theme throughout my discussions with administrators was the limitations inherent in meeting the needs of their residents as a result of the limited funding provided by the Ministry of Health and Long-Term Care, in particular with regard to their dietary preferences. Four of the seven administrators interviewed indicated that shortfalls in funding limiting the ability to meet the dietary preferences of their residents were alleviated through funding top-ups, either through fundraising and community contribution or as a result of corporate decisions to provide assistance in this area.

Despite additional resources sought to meet the cultural needs of residents, the nature of long-term care regulations limit to what extent these requests can be met. The Long-term Care Act (2010) requires that long-term care providers follow Canada's Food Guide in menu planning. Two of the respondents indicated challenges in providing culturally familiar menus as a result of this, as traditional diets for their target ethnic group do not meet Canada's Food Guide. One respondent stated, 
...in that we have to meet the ministry guidelines and the ministry regulations, so we can't do completely ethno-specific because they wouldn't meet Canada's Food Guide requirements. They don't have enough protein, they have other things, but they don't have enough protein in their diet. (personal communication, August 2, 2012).

In discussions on Canada's Food Guide and legislation set forth by the ministry, another respondent stated:

The government wants it to be home like but at the same time you have to meet all these guidelines, and so it becomes so schizophrenic in a way; at the same time they promote residents first and consumers choice. It's so highly regulated, you cannot give them choices, because if you give them choices you break the rules. (personal communication, August 17, 2012). In addition to regulations governing the dietary requirements for each facility posing a problem, so too did regulations pose another problem for one facility in staffing for a chef position. The ministry requires that all staff employed as chefs hold a diploma or certificate from a recognized culinary institute. As the administrator in question asserted,

Those people who go to college to become a chef, they are not interested in working for long-term care. These programs are not preparing you to be a Chinese chef; they're preparing you to be a French chef. So the legislation requires us to hire a cook with that kind of training and background...we have a couple of them that do have the training background. But let me tell you, they may not be the best chef in cooking 
Chinese food, in cooking it in a way that generation is used to. (personal communication, August 17, 2012).

Challenges associated with regulations were also identified as a factor in providing culturally appropriate nursing care. This was of particular concern for Chinese immigrants, who often practice traditional Chinese medicine in tandem with more western approaches to medicine. Two of the respondents indicated that physicians were reluctant to practice Chinese traditional medicine because of professional codes of conduct and the potential liability that accompanies licensed physicians prescribing these methods. Herbal medicine physicians are not licensed in Ontario, and therefore cannot be the prime attending physician for the residence. However, it was noted that although physicians may be reluctant to prescribe or advise on these practices, it is within the resident's rights to engage in culturally familiar practices, should they be able to gain access to them.

A common theme throughout six of the seven interviews was the challenge associated with current immigration regulations and the effect this has on access to sufficient staff fluent in the native language of their residents. Some groups faced greater challenges than others. This was particularly true for staffing in European facilities compared to their Asian counterparts. As immigration patterns change over time, so too does the supply of workers fluctuate. As one administrator of a predominantly European facility indicated,

...[the new worker pool] all come from Asia. And so unless they have a sponsor it's difficult [for workers from Europe to migrate]. Because you have to do a national ... survey and if there's anyone in Canada that wants 
the job that's Canadian, they get it, but we need [principal language spoken in residence] speaking people who can communicate with our residents but they don't really consider that a reason to give them a work permit. (personal communication, August 16, 2012).

As well, credential recognition of newcomers was identified as a challenge to employing native language speakers by three of the respondents.

\section{Cultural disconnect}

A common barrier identified by respondents was the cultural disconnect between staff and residents. As Canada faces a shortage of workers, we are increasingly relying on immigrants to fill care positions in long-term care, particularly those in ancillary or nonprofessional positions (Bourgeault, Atanackovic, Rashid \& Parpia, 2010); however, source countries for workers do not necessarily match source countries for older immigrants. There can therefore be a great degree of cultural disconnect between caregivers and residents. Four of the respondents indicated that cultural misunderstandings are common, resulting in tension between staff and residents. The historical context of immigration and pre-immigration conditions for many of the older immigrant residents are often not understood by staff, many of whom have come to Canada with their own immigration-related challenges.

The cultural disconnect is evident in the provision of nursing care, particularly concerning end-of-life care practices. Two respondents discussed the challenges surrounding cultural preferences for end-of-life care encountered within their facilities and the perceptions of staff towards them, as follows: 
There's a few issues around end-of-life choices that are quite different from western culture and what we believe, and so there are some conflicts of ethnic beliefs that staff have come to speak to me about to say, "Can't you talk to this family"... "it's mean, it's cruel... what we're doing to prolong this person's life." But that's their choice and we have to learn it, and so there's the need for a lot of education around cultural differences. I would say the norm is, maybe $10 \%$ of the residents would be full-code ${ }^{7}$, you know for end-of-life choices. Here it's 90\%. (personal communication, August 2, 2012).

Another administrator, in discussing how death is handled in various communities, recounted the following:

I remember, from a Sikh client, facing death we were told not to touch the person, don't hold their hand, even though our instinct is to do so and provide comfort...because...it's an accepting process, and you need to let that person be, don't hold them, because you're holding on, you have to let them go peacefully. (personal communication, August 17, 2012).

Both administrators indicated that continued education initiatives alleviate this disconnect; however, it is a constant learning process.

Cultural disconnect also exhibited itself in providing day-to-day personal care for residents. As previously mentioned, the historical elements of a culture may not be known or fully understood by all staff. One Jewish long-term care facility administrator discussed the challenges for staff and residents when addressing personal care. Many of

\footnotetext{
${ }^{7}$ Full code refers to the resuscitation orders on a resident's file. Full code indicates that all measures are to be taken to resuscitate the resident, regardless of their health, condition, or quality of life.
} 
the Jewish immigrants residing in long-term care facilities today have memories of the Holocaust. Whether concentration camp survivors themselves, refugees escaping persecution, or immigrants and Canadian-born who had family and friends perish, the impact of these memories can prove to be paralyzing. As she discusses,

...we have residents that don't want to have a shower, because they were sprayed upon during the Holocaust. So the staff is thinking, "they don't want to have a shower", but it's not because they don't want to shower, it's because it brings back bad memories. (personal communication, July $31,2012)$.

Staff members are therefore required to go through annual training on the Jewish culture, which includes education on the Holocaust and Jewish persecution throughout history. Cultural disconnect is also apparent in the interpersonal relationships between residents and staff. As many long-term care facilities rely on immigrant staff whose cultural background may be very different from that of the client base, different practices may cause strife between residents and staff. Four of the respondents indicated that cultural practices and norms of staff have caused challenges for care provision. As one administrator stated, "Their attitude towards seniors or elderly is quite different. Some of them will call them Mama or Papa out of respect, because that's their culture, but in western culture, that's not considered proper." (personal communication, July 31, 2012). Another administrator indicated that, "Some cultures speak in a louder voice than others. Sometimes the residents think the person is yelling and being aggressive, but it's just the way they've been brought up to talk. It's normal for them." (personal communication, August 22, 2012). All three administrators who addressed this issue indicated that 
continued education, primarily for staff and family members who are advocates for residents in care, was the preferred way to deal with such conflicts.

\section{Inter/intra-ethnic conflict}

One of the challenges I did not anticipate pertains to inter-ethnic and intra-ethnic conflict, both among residents as well as among staff and residents. Because of historical events that have divided various groups, ethnic-based conflicts occurred in the long-term care setting. One respondent recounted the difficulties encountered between Jewish and German residents, as racial slurs and insults had become a common problem between two residents. As well, the fear of the 'other' seemed to be present in some of the stories recounted by administrators. In one residence -a home which had initially been created for one particular ethnic group, but which, through demographic shifts in the area and increased immigration from other parts of the world compared to the initial target group, had shifted ethnic focus to the newer, more predominant group. One resident had expressed great disdain for this, bringing the complaint to the Ministry of Health and Long-Term Care. As the administrator recounted, "I get a number of [original ethnic group] residents come down with the whole issue of, 'Why are we catering to the [principal ethnic group] residents when this was our home?"' (personal communication, July 20,2012). This is a reality of long-term care, as, despite the existence of ethnospecific facilities, residences cannot reject admissions based on race or ethnicity. Therefore, a mix of ethnicities often occurs, with the principal ethnicity often reflecting the principal ethnicity of the geographical area.

Inter-ethnic conflict also occurs quite frequently between staff and residents. This has been widely documented in research on cultural care (Bourgeault et al., 2010). As 
stated earlier, Canada is increasingly relying on immigration to fill the gaps in the labour market, including in health care. Ethnic minorities are highly represented in ancillary and low-skill positions within health care services. Systemic and historic racism is often exhibited by residents towards their caregivers. This can be exacerbated by the onset of dementia and the inability of the resident to fully comprehend the situation. Two of the administrators interviewed indicated that this was one of the biggest challenges they deal with in providing care to their residents. In the words of one administrator:

Our biggest challenge is when families request not having coloured staff. Because that's the generation that grew up that way, and you know it's not right, but that's how they grew up. So you can't do anything about it, because they're at that age and cognitive ability where they won't change, so we try to work with our staff and try to get them to understand that it's not personal. But it's hard. And believe me, some of the names these people come up with. But it's reality. They grew up with having servants who were that colour, and they would boss them around. (personal communication, July 31, 2012).

In both facilities that identified this as a challenge, staff are made aware of the potential for racism upon being hired. Efforts are made by the management to curb these incidents, and accommodations are made should a staff member report that they are not comfortable working with a particular resident.

\section{Effects of dementia}

Dementia plays a significant role in how culturally appropriate care is designed and delivered. All seven administrators highlighted dementia as a key challenge in long- 
term care today. This is a significant development in long-term care, as the incidence of dementia doubles every five years after the age of 65 and exceeds $30 \%$ of the population age 85 and older (Kaplan \& Berkman, 2011).

The challenges associated with dementia are varied. Paranoia, confusion, forgetfulness, and extreme anxiety are common characteristics of dementia (Kaplan \& Berkman, 2011). Managing this in an institutional environment is nothing short of challenging. The addition of immigration-related factors contributes to a double-jeopardy hypothesis for older immigrants (Dowd \& Bengtson, 1978). As discussed earlier, Jewish residents in one ethno-specific facility are mentally oriented toward their earlier years. For some, this brings back the horrors of the Holocaust, affecting their ability to cope with daily activities. Moreover, dementia requires adjustment of how care is provided, as increased sensitivity and agitation are often symptoms. Stimulation exercises, therefore, must be designed with these needs in mind. Two of the facilities visited had introduced snoezelen rooms, a multisensory environment used as therapy for those with cognitive impairments, developmental disabilities, and autism (Chung et al., 2002). Residents with dementia benefited greatly from this therapy, with a marked reduction in aggressive behaviours.

As indicated earlier, many residents with dementia experience the loss of their second language as the disease progresses. This creates grave challenges for service provision and care, increasing the vulnerability of residents to disease, illness, and culturally foreign practices. This was indicated by all administrators interviewed to be one of the greatest challenges in providing care to older immigrants. 


\section{DISCUSSION}

The purpose of this research was to examine how culturally appropriate care is being delivered in ethno-specific facilities in order to formulate a set of best practices and lessons learned that could be applied to other long-term care environments. Overall, the findings support the argument that ethno-specific long-term care facilities are designed to meet the cultural care needs of older immigrants, thereby reducing the environmental stress of institutional living. The research findings indicate, however, that a number of culturally-specific challenges exist to meeting the needs of older immigrants. I identified seven main themes in the findings: ease of interaction; cultural norms; the extension of community; systemic issues; cultural disconnect; inter/intra-ethnic conflict; and the effects of dementia-related disorders on care provision. Both successes and challenges are outlined below, followed by a discussion on the contributions this research makes to the literature on culturally appropriate long-term care of elderly immigrants, as well as areas for further research.

\section{Ease of interaction}

Overall, the ability to communicate in one's first language was determined to be a critical element in long-term care. Respondents overwhelmingly felt that the presence of staff that speak the principal language and are therefore able to understand the needs of residents greatly reduced the environmental stress on residents. This is consistent with much of the literature on settlement and integration in Canada, as well as understanding barriers to accessing health care. Language capacity in one of Canada's official languages has been a critical measure of successful settlement and integration (Kim, Ehrich \& 
Ficorilli, 2012; Stewart, Neufeld, Harrison, Spitzer, Hughes, Makwarimba, 2011). The isolation that occurs when one cannot adequately communicate personal needs can act as a significant limitation for care within the long-term care sector. Health issues can go unnoticed or be misdiagnosed, resulting in further complications and reduced competency (Brotman, 2002; Lai, 2002).

The availability of staff who spoke the principal language presented a challenge for some ethno-specific facilities, particularly those that were geared towards ethnic groups coming from Europe. As Bourdeault et al. (2010) discuss, newer waves of immigrants, predominantly from Asia and the Caribbean, are increasingly filling the lowskilled, ancillary positions within health care settings. With a reduction in European immigration to Canada, there exists a shortage of nursing-related professionals who can speak the languages of certain older ethnic groups.

The challenges associated with older European minority groups have been largely ignored in recent literature. Although language as a barrier to accessing health care services has been well documented, it has focused primarily on newer groups of immigrants, in particular the experience of Asian and Southeast Asian communities. As immigration patterns shift, and European immigrants become the minority instead of the majority in Canada, this is an area that will require further research.

\section{The importance of cultural norms}

Cultural norms form the foundation for cultural care. Therefore, adherence to cultural norms and values permeated the majority of programs delivered by ethnospecific long-term care facilities. This includes tailoring menus to include culturally familiar foods; observing traditional holidays; engaging in culturally familiar activities; 
and an observance of the various religions practiced by the residents. Enabling a continuity of familiar practices greatly diminishes the environmental stress of institutional living. This supports the existing literature on cultural care; as Yeo (1993) argues, the provision of a culturally relevant diet, targeted activity programs and observance of religious practices that are in line with the various belief orientations of the residents are critical in providing cultural care. Moreover, the primacy of food as a cultural reference point was repeatedly reinforced through discussions with long-term care administrators. This reinforces earlier arguments presented by Kaplan \& Shore (1993) supporting the need for culturally appropriate care, as it provides the environment for shared cultural practices, including special foods and traditions associated with the rituals of food for many cultures. Having the organizational capacity to address education among staff about the cultural practices of the residents also greatly influenced the successful implementation of cultural care initiatives.

\section{A need for building a sense of community}

The loss of community for older immigrants entering long-term care has been identified as a significant stressor in the literature on ethnicity and long-term care (Lai, 2005; McDonald, 2011; Stephens, Alpass, Towers \& Stevenson, 2010). Although a number of respondents discussed the issue of isolation as a result of the institutionalization process, the rebuilding of community ties in ethno-specific care was integrated into the planning and implementation of all programs. As Kaplan \& Shore (1993) discuss, culturally appropriate care provides an environment for shared heritage and observance of one's cultural practices that is free of judgment and where immigrants can “...feel understood, wanted, protected and nurtured." (p. 116). Creative approaches to 
recreating community were identified, including designated wards for certain ethnic or linguistic groups; building inter-cultural ties through common activities with different ethnicities in the facility; and activity programs that bring members of the ethnic community into the facility to provide entertainment. Indeed, it is possible that ethnospecific long-term care may build stronger community ties than many older immigrants experienced when living in the community post migration. The literature on isolation among older immigrants suggests that, for certain older immigrants, the immigration experience brings with it a great sense of isolation from others who have shared heritage and cultural background. There is a significant body of literature on the living arrangements of older immigrants who come to Canada for family reunification that details how many, upon arrival, are not able to reconnect with their ethnic community through geographic isolation, familial responsibilities, and barriers to transportation (Cheu \& Lai, 2002; Lewis-Watts, 2008; Treas, 2009). The community approaches in ethno-specific long-term care may alleviate this for some groups; however, this is an area that would require further research.

\section{Systemic issues and cultural disconnect}

Although cultural understanding was deemed to be a critical element in providing cultural care, the capacity for many facilities to address this issue varied. This was due to a number of reasons, some of which I had not anticipated prior to my research. Systemic challenges present in the institutional frameworks for long-term care create a system that does not allow the flexibility to respond to certain cultural needs of the residents. Although a few authors have examined cultural disconnect within long-term care (Brotman, 2003; Disman \& Disman, 
1995; Friedman, 2006), few, if any, have addressed the bureaucratic and regulatory limitations on meeting the needs of older immigrants. As one administrator noted,

I'm all for regulation, don't get [me] wrong... yes, set the rules against abuse, set rules against bad practices. But in order to allow good practices, you need to allow some flexibility. You can penalize and sanction bad behaviour, but don't stifle good practices, so that truly residents have a choice and truly those cultural needs can be met. (personal communication, August 17, 2012).

This might be best addressed by what Harris and Grootjans (2006) argue is a shift in orientation as to how elder care is being approached. Moving from a predominantly medical and curative approach to care of the aged, to one that favours quality of life, innovative approaches are being introduced to meet the needs of the aging population. Culturally appropriate care, informed by the best practices and lessons learned in ethnospecific long-term care, may foster a shift in practice and allow increased flexibility in how care is delivered. As the institutional approach has, until recently, been a foreign practice for many immigrant families from non-Western nations, flexibility may be critical to addressing this need.

As Leininger (1988) argues “...care is the essence of nursing and the central, dominant, and unifying feature of nursing." (Leininger, 1988, p. 152). Moreover, her theory of cultural care reinforces the need for culturally based frameworks to guide nursing care, as care and culture are inextricably linked and cannot be separated in nursing care actions and decisions (Leininger, 1988). This was expressed as a significant 
concern for newer immigrant groups in Canada, whose cultural practices have been less influenced by Western practices than those of the historically European base of immigrants to Canada. The challenges to providing traditional care continue to be of concern for many of these groups, as the long-term care sector is still guided by predominantly Western-based models and regulations surrounding how care is delivered.

\section{Inter/intra-ethnic conflict}

Inter/intra-ethnic conflict was an additional challenge I did not foresee when designing the research. Although this research was aimed at addressing the cultural needs of older immigrants in long-term care, the wellbeing of those providing this care requires attention. As the data show, cultural differences between staff and residents can create challenges for the delivery of care. This is not limited to ethno-specific care facilities. Indeed, as described by Scott, Ryan, Assumpta \& Mitchell (2011), working with clients suffering from dementia can often lead to abusive situations. The reliance within longterm care on immigrant workers, and the racism subsequently encountered by this population of service providers, creates other debates surrounding immigration and longterm care. This is an area that may require further study.

\section{The challenges of dementia-related disorders in providing culturally sensitive care}

The increased incidence of dementia-related disorders create challenges for all care delivery. The foreign environment and practices present in mainstream long-term care may exacerbate this. The challenges associated with dementia permeate all areas of care, and increase the demands placed on caregivers. This is not an immigration-specific issue; however, as a number of authors have argued, older immigrants are susceptible to a 
number of settlement-related challenges reflected in the double-jeopardy hypothesis.

Dementia adds an additional dimension to this challenge. The onset of various dementiarelated disorders can create challenges for understanding among older immigrants as to why they are in long-term care. The foreign environment for many older people creates greater confusion and challenges for addressing dementia-related behaviours. Temporary alleviation of challenging behaviours and signs of the disease was reported to be successful with the provision of culturally appropriate services; however, dementia is a complicated umbrella of cognitive impairments that require intervention beyond what culturally appropriate care can provide.

\section{Unanticipated findings}

One of the challenges to care for older immigrants that I had not included in my research design, yet frequently was discussed as being of concern, was the impact of familial guilt on the operations of the facility. There exists a significant body of literature on the familial responsibilities and cultural expectations for care provision among many immigrant groups (Lai, 2002; McDonald, 2011; Treas \& Mazumdar, 2002; Wister et al., 1996). The generational shift occurring today, with institutional care becoming increasingly acceptable among younger minority group members who previously would have cared for their elders at home, continues to clash with the expectations of many older immigrants, many of whom came to Canada under the assumption of family reunification, and who often do not share the belief of their grown children regarding institutional care. Indeed, many find themselves feeling depressed and isolated when they are transferred from their homes into institutional care. The concept for many is unconscionable, and can often be interpreted as a rejection by their children (Treas \& 
Mazumdar, 2002). During my research, this theme was expressed by three of the administrators, one of whom indicated it created challenges in the delivery of care, as often residents' families would make unreasonable or extreme requests for accommodating their parents, primarily out of guilt. One administrator noted that they had offered family counseling to their residents' families in order to allow a space for open discussion on issues such as these.

\section{Limitations of the research}

The chosen method does lend itself to some key challenges. Firstly, it takes into consideration the best practices and lessons learned in providing culturally appropriate care to the principal ethno-cultural group of each facility only. This excludes any concerns or issues that may be affecting the entire population of the facility, which could potentially contribute to the discourse on health care provision to older immigrants and the challenges associated therein. Moreover, this excludes any discussion of other ethnospecific groups who, for various reasons (i.e., lack of organizational resources in the community, cultural beliefs surrounding institutionalization), do not have access to ethnospecific care facilities. The research therefore reflects those groups of immigrants and their descendents who have had the privilege of successfully navigating the health care system and are well established within the GTA. Finally, the data do not encompass the perspective of older immigrants living in long-term care facilities, therefore excluding a critical element in evaluating the success and challenges within ethno-specific care facilities according to those whom the services are geared towards.

The decision to interview administrators rather than residents themselves was based on a number of factors. Firstly, seniors in long-term care settings are a vulnerable 
population. As Schuster (1996) discusses, there is a high degree of external control on the lives of residents in long-term care facilities, so that controlling and symmetry aspects of the relationship between the researcher and the participant become more significant than in settings where participants have a higher degree of autonomy. This can create the potential for a number of ethical challenges, as responses about care received may put the participant in a vulnerable position with caregivers. Secondly, the prevalence of cognitive impairment within this population would limit their ability to participate without causing undue stress to them. Thirdly, many are not fluent in either of Canada's official languages. Translators in a number of languages and dialects would have been necessary in order to reach this population. Resource constraints within this study did not permit hiring translation services. Finally, and most importantly, the research was designed to be an exploratory study of best practices and challenges in providing culturally appropriate care from a service provision perspective. Therefore, targeting the administration element of ethno-specific care rather than resident perspectives was deemed to be the more appropriate line of inquiry. Further research that includes the perspectives of residents and/or their families would triangulate the data to validate administrator responses of how effective ethno-specific long-term care programs are at meeting the cultural needs of older immigrants.

As all participants were guaranteed confidentiality with their participation in the study, the data have been coded in a manner that protects the identity of each response. Although this creates a complication in understanding how various ethno-specific groups have navigated the long-term care system in order to meet the needs of their clientele, the importance of maintaining confidentiality was deemed paramount. One of the downfalls 
of conducting this research is that it may be somewhat subjective and have inherent biases, as respondents have professional as well as community responsibilities in providing care. Again, triangulation of data through the use of multiples sources would possibly serve to validate or qualify in some way the responses provided by administrators on the challenges they face and their means of meeting them in this vital area of providing culturally sensitive care.

\section{Contributions to the literature and areas for further research}

The literature to date on the cultural needs of older immigrants in long-term care has focused primarily on the challenges faced by older immigrants living in mainstream long-term care settings. By introducing the ecological model for cultural care and adaptability as the theoretical lens, the research findings contribute to expanding the literature on best practices for meeting the needs of older immigrants in long-term care, taking into consideration how programs that reduce the overall environmental stress on older immigrants in institutional settings. Moreover, because the research design focused solely on ethno-specific facilities that are at the forefront of addressing the gap in service to older immigrants in Canada, and specifically within the GTA, the research addresses the gap in existing literature, which has been heavily biased towards experiences within the United States.

The findings overall are consistent with the literature on cultural care that argues for greater cultural congruence in service provision to meet the needs of older immigrants. Culturally appropriate services within ethno-specific long-term care have been designed to support this need, reducing the strain experienced by older immigrants as they enter institutional care. This research goes beyond this, as it provides a logical 
template populated with best practices and lessons learned for practitioners and researchers to utilize in designing programs of ethno-specific long-term care.

My research took a broad approach to ethno-specific care, as I did not focus on one particular ethnic group. It is therefore not easy to generalize about the practices put in place in various long-term care facilities without losing the nuances of how they have been tailored to meet the specific health-related needs of their residents, including their life-course and immigration experience, and encourage a better quality of life. This does present some limitations, as the culturally specific practices of diverse ethnic groups, resources available to address certain challenges, and the support of the ethnic community differ greatly, allowing some ethnic groups to thrive in long-term care, whereas others face greater challenges. Focused and directed study on how particular ethnic groups design cultural care is needed in order to better assess how specific cultural programs are reducing the environmental stress in long-term care.

As with all human service provision, there will be challenges that are worthy of future research. Firstly, there is a need to examine the systemic barriers of providing culturally appropriate care to older immigrants. Programs that are targeted towards addressing cultural needs can be improved with increased flexibility within the system that allows for considerations of the needs of older immigrants. Secondly, although this was not addressed as part of the research questions, the shift in immigration policy concerning sponsorship of parents and grandparents discussed in the introduction may bring about new challenges for long-term care and how older immigrants are accessing services. Parents and grandparents coming to Canada through the new "Parent and Grandparent Super Visa" designed to allow visits to family in Canada for up to two years 
will not be entitled to health benefits within Canada, but rather are required to carry private health insurance during their stay (CIC, 2011b). Long-term care services will therefore be out of reach for those coming to Canada under the "Super Visa". Lastly, with the decline of parent and grandparent sponsorship, more immigrants accessing longterm care in the future will most likely have immigrated to Canada at an earlier stage in their lives. Many will have come to Canada through skilled worker programs, with knowledge of one official language, as well as a number of other attributes that may facilitate settlement and integration. With a longer acclimatization period in Canada, the possible shift in attitudes and cultural norms of this demographic group may impact the shape of ethno-specific long-term care, aligning it to a greater extent with mainstream long-term care. 


\section{CONCLUSIONS AND RECOMMENDATIONS}

Older immigrants face a number of settlement- and integration-related challenges. As Dowd and Bengtson (1978) argued, older immigrants face a double jeopardy due to age and ethnicity, placing them at greater disadvantage than their Canadian-born counterparts. Long-term care that does not address the cultural needs of older immigrants as they encounter declining health can place older immigrants at an even greater disadvantage than their Canadian-born peers.

The application of the ecological model for culturally sensitive care for older immigrants highlights the critical role that culture plays in alleviating the environmental stress present through the institutionalization process. The absence of culturally appropriate care in mainstream long-term care facilities can create environmental stressors that weigh heavily on those with decreased individual competency. The presence of ethno-specific long-term care facilities designed to address the cultural elements of individual ethnic groups can significantly reduce the stress on older immigrants as they adjust to a new and unfamiliar setting.

The strength of ethno-specific care programs for older immigrants goes beyond the initial adjustment period. As the research findings demonstrated, the ability for older immigrants to converse in their native language, the observance of cultural norms such as religion and health care practices, and the rebuilding of a lost sense of community reduce a number of stressors on older immigrants in care. Firstly, the opportunity to converse and be understood in one's native language decreases the incidence of isolation, while also increasing the quality of care received, as residents are able to better express their health-related needs. Secondly, the observance of cultural norms, which forms the 
foundation for cultural care, can increase the ties older immigrants feel towards their traditions, many of which are intrinsic to their way of life and beliefs about health. As the health-related challenges of aging begin to exhibit themselves, in particular dementiarelated illness, many residents in long-term care retreat mentally to the past. This is often back to pre-migration periods in their lives; the presence of culturally familiar elements can therefore reduce the anxiety and fear associated with foreign cultural norms. Thirdly, the rebuilding of lost community, as previously mentioned, can alleviate not only the loss of community when moving into a long-term care facility, but for some older immigrants, may provide the first sense of community post migration.

The provision of ethno-specific care also presents a number of challenges, which have been referred to in the research as 'lessons learned'. The systemic issues present in long-term care regulations and design, the cultural disconnect between staff and residents, and the inter/intra-ethnic conflicts that occur all require attention in design and delivery of ethno-specific long-term care. In addition, the overwhelming challenges of service provision to those with dementia-related illness place an additional strain on service design and delivery. Firstly, the model and legislation for long-term care has been designed based on Western ideas of care. Despite providing a culturally familiar environment, there are limitations as to the extent that long-term care facilities can adjust practices to align with culturally familiar ones. Adjustments to regulatory frameworks and legislation, both within long-term care as well as within various professional colleges, to recognize the demand for culturally appropriate services are needed. Secondly, a cultural disconnect between staff and residents poses a problem for care relationships, and can increase the environmental stress on residents. As Canada's 
immigration trends show, labour shortages are being addressed through increased immigration from non-traditional source regions such as Asia and Southeast Asia. Differing opinions about culture and care can often pose challenges to the delivery of care. This issue does not solely stem from ethnic minority or immigrant workers. Canadian-born staff face similar issues in understanding the cultural nuances that motivate decisions on care for older immigrants. Thirdly, inter/intra ethnic conflicts within ethno-specific long-term care facilities, often a product of historical racism and inter-ethnic strife, pose challenges to care, and can place stress on residents and staff. Although this is not specific to long-term care settings, the stress of conflict in the environment often increases feelings of isolation and confusion and reinforces negative stereotypes and historic patterns of racism. This is often exacerbated by the presence of dementia, which places excess strain on both the caregivers and the resident.

By evaluating best practices and lessons learned in ethno-specific long-term care, the research demonstrates that ethno-specific long-term care is designed to meet the needs of older immigrants. The increase in immigration to Canada, and the aging of the current population, will fuel the demand for better design of health care services, in particular residential long-term care. Culturally appropriate long-term care that continues to evolve from this model will be better situated to address the diverse needs of an increasingly ethnically diverse population.

The data gathered highlight strengths and weaknesses in the provision of ethnospecific care. In light of this, I will address some recommendations. Firstly, best practices and lessons learned need to be shared broadly among the long-term care community, as there are opportunities for knowledge exchange and shared learning that could lead to 
addressing some of the challenges encountered. Secondly, staff training should incorporate educational components that provide care providers with a better understanding of cultural traditions, the intersection of spiritual beliefs with care practices, and the historical context of ethno-specific immigration experiences. This could alleviate some of the stress experienced by both staff and residents in attempting to address cultural needs. Finally, there is a need for integrated approaches to dementiarelated behaviours and cultural traditions that also takes into consideration the immigration experience of specific ethnic groups. This may lead to the creation of best practices for addressing dementia-related behaviours and stressors in ethno-specific settings. 


\section{Appendices}

\section{Appendix A - Interview Questionnaire}

Culturally appropriate care for older immigrants in the long-term care sector Interview guide

1 - What is the facility policy on culturally appropriate care provision?

2 - What are the main concerns staff face in addressing the cultural needs of older immigrants (e.g. language barriers, nursing practices, religious accommodation, dietary practices) and how do these challenges manifest themselves?

3 - What programs are in place to address the following issues? How successful is each one?

$$
\begin{aligned}
& \text { A - nursing care } \\
& \text { B - language barriers } \\
& \text { C - cultural traditions (including religious observance) } \\
& \text { D - dietary practices } \\
& \text { E - recreation programs }
\end{aligned}
$$

4 - In your opinion, do the programs and practices aimed at alleviating the stress of cultural disconnect improve the lives of your older immigrant population? How?

5 - Are there any other culturally specific needs that were not covered that the facility addresses?

6 - What issues arise in terms of requests for accommodating cultural practices (e.g. family satisfaction, resident satisfaction, community requests)? 


\section{Appendix B - Ecological Model for Culturally Sensitive Care for Older Immigrants: Best Practices and Lessons Learn Template}

\begin{tabular}{|c|c|c|c|c|c|}
\hline & Needs & Adaptations & Environmental Stressors & Best Practices & Lessons Learned \\
\hline Language & $\begin{array}{ll}\text { - } & \text { Communicate health } \\
\text { needs } \\
\text { - } \quad \text { Converse with } \\
\text { neighbours } \\
\text { - } \quad \text { Read pertinent } \\
\text { information }\end{array}$ & 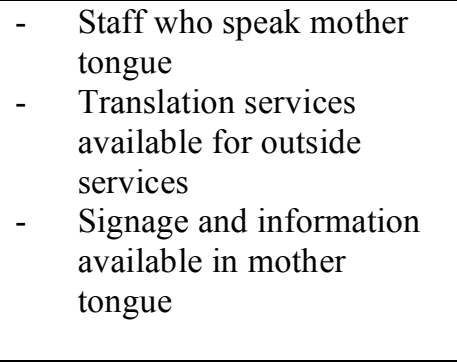 & $\begin{array}{ll}\text { - } & \text { Inability to } \\
\text { communicate } \\
\text { sufficiently to staff in } \\
\text { common language } \\
\text { - } \quad \text { Lack of knowledge of } \\
\text { health issues } \\
\text { - } \quad \text { Loss of } \\
\text { speech/second } \\
\text { language }\end{array}$ & $\begin{array}{ll}\text { - } & \text { Availability of staff who } \\
\text { speak principle language } \\
\text { - } & \text { Use of adaptive tools to } \\
\text { address gaps in language } \\
\text { - } \quad \text { Language training for staff }\end{array}$ & 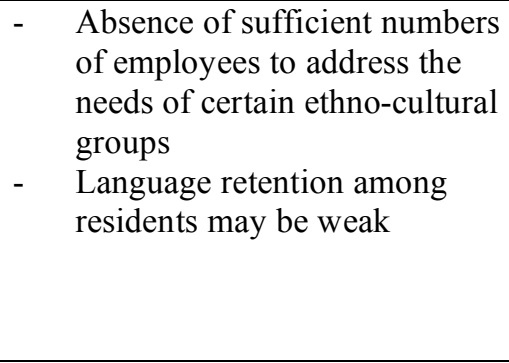 \\
\hline Food & $\begin{array}{ll}- & \text { Nutritious food } \\
- & \text { Address specific } \\
& \text { dietary requirements } \\
- & \text { Traditional food } \\
& \text { practices }\end{array}$ & $\begin{array}{ll}\text { - } & \text { Availability of culturally } \\
\text { familiar foods } \\
\text { - }\end{array}$ & $\begin{array}{ll}\text { - } & \text { Inability to prepare } \\
\text { one's own food } \\
\text { - } & \text { Shared environment } \\
\text { limiting space for } \\
\text { traditional practices }\end{array}$ & $\begin{array}{ll}- & \text { Multiple menu choices } \\
\text { - } & \text { Regular input from } \\
\text { residents and families on } \\
\text { menu } \\
\text { - }\end{array}$ & $\begin{array}{ll}- & \begin{array}{l}\text { Regulatory limitations to } \\
\text { delivery of purely ethno- }\end{array} \\
\text { specific diet } \\
\text { - } & \text { Regulatory requirements for } \\
\text { staffing position of chef } \\
\text { - } \\
\text { Cost of multiple ethno-specific } \\
\text { menus }\end{array}$ \\
\hline Religion & $\begin{array}{l}\text { Observance of } \\
\text { religious practices in } \\
\text { daily life, religious } \\
\text { rituals, and care }\end{array}$ & $\begin{array}{ll}\text { - } & \text { Regular religious services } \\
\text { in dominant religions } \\
\text { - } & \text { Celebration of culturally } \\
\text { specific religious holidays } \\
\text { - } \\
\text { Daily practices that } \\
\text { conform to religion- } \\
\text { specific traditions }\end{array}$ & $\begin{array}{ll}\text { - } & \text { Attending services } \\
\text { difficult (ambulatory } \\
\text { and cognitive } \\
\text { function limited) } \\
\text { - } \quad \text { Services limited }\end{array}$ & $\begin{array}{ll}\text { - } & \text { Education for staff } \\
\text { surrounding religious } \\
\text { practices, historical context } \\
\text { of immigration } \\
\text { - } \\
\text { Regular religious services } \\
\text { provided to residents that } \\
\text { meet all the religious } \\
\text { denominations in residence }\end{array}$ & 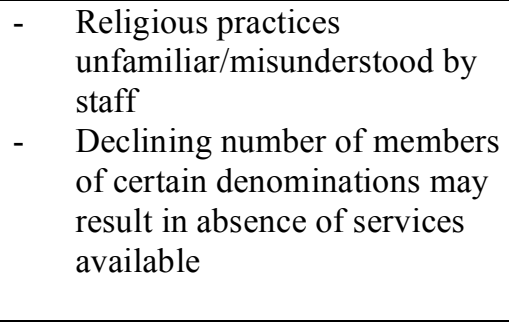 \\
\hline
\end{tabular}




\begin{tabular}{|c|c|c|c|c|c|}
\hline & Needs & Adaptations & Environmental Stressors & Best Practices & Lessons Learned \\
\hline $\begin{array}{l}\text { Recreation/ } \\
\text { Leisure }\end{array}$ & $\begin{array}{ll}- & \text { Regular } \\
& \text { interaction/activities } \\
- & \text { Retain elements of } \\
& \text { cultural heritage }\end{array}$ & $\begin{array}{ll}\text { - } & \text { Activities that are } \\
\text { culturally familiar } \\
\text { - } \\
\text { Inclusion in activities of } \\
\text { the ethnic community } \\
\text { - } \\
\text { Activities that promote } \\
\text { cultural } \\
\text { continuity/language }\end{array}$ & $\begin{array}{ll}- & \text { Attending events } \\
\text { difficult (ambulatory } \\
\text { and cognitive } \\
\text { functioning limited) } \\
\text { - } \quad \text { Services limited }\end{array}$ & $\begin{array}{l}\text { - Utilize a range of cultural } \\
\text { activities } \\
\text { Tailor activities to meet the } \\
\text { capabilities of residents and } \\
\text { their cognitive and } \\
\text { ambulatory functioning } \\
\text { - Use of traditional activities } \\
\text { that are culturally familiar } \\
\text { - Group residents according } \\
\text { to capabilities and cognitive } \\
\text { functioning for activities }\end{array}$ & $\begin{array}{ll}- & \text { Variety of levels of } \\
\text { functioning creates frustration } \\
\text { among participants } \\
\text { - } \quad \text { Funds to run targeted } \\
\text { programs for each ethnic } \\
\text { group may be limited }\end{array}$ \\
\hline Nursing care & 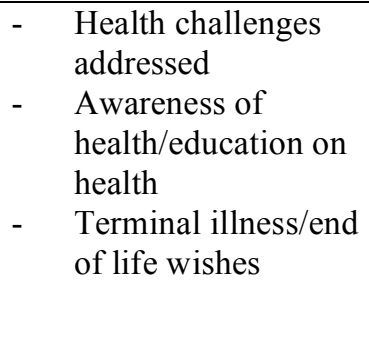 & $\begin{array}{ll}\text { - } & \text { Culturally appropriate } \\
\text { care practices } \\
\text { - } & \text { Use of traditional health } \\
\text { practices of dominant } \\
\text { cultures } \\
\text { - Adherence to cultural } \\
\text { norms and practices } \\
\text { surrounding terminal } \\
\text { illness and death }\end{array}$ & $\begin{array}{ll}\text { - } & \text { Inability to } \\
\text { communicate } \\
\text { wishes/needs } \\
\text { - } \quad \text { Needs contravene } \\
\text { practices supported in } \\
\text { facility }\end{array}$ & $\begin{array}{ll}\text { - } & \text { Set out care plan with the } \\
\text { assistance of family and/or } \\
\text { interpreter if needed } \\
\text { - } \quad \text { Revise care plan regularly } \\
\text { - } \quad \text { Provide access to traditional } \\
\text { nursing practices and end of } \\
\text { life care } \\
\text { - } \quad \text { Educate nursing staff on } \\
\text { end of life practices }\end{array}$ & 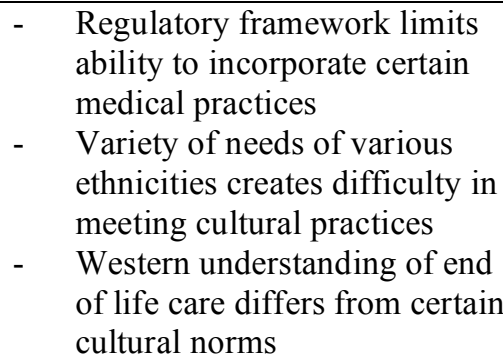 \\
\hline
\end{tabular}




\section{References}

Abramson, H. (1980). Assimilation and Pluralism.. In S. Thernstrom (ed), Harvard Encyclopedia of American ethnic groups (pp. 150-160). Cambridge, MA: Harvard University Press.

Alternative Planning Group. (2009). Citizenship matters: Re-examining income (in)security of immigrant seniors. The Community Perspective Series, Toronto: Wellesley Institute.

Andersen R. \& Newman, J. (1973). Societal and individual determinants of medical care utilization in the United States; Milbank Memorial Fund Quarterly-Health and Society 51(1), 95-124.

Baker, M., Bejamin, D., Fan, E. (2009). Public policy and the economic wellbeing of elderly immigrants. Canada Labour Markets and Skills Researcher Network, Working Paper \#52.

Barresi, C. \& Stull, D. (1993). Ethnicity and long-term care: An overview. In C. Barresi \& D. Stull (eds), Ethnic elderly in long-term care (pp. 3-21). New York: Springer Publishing Company.

Bourgeault, I., Atanackovic, J., Rashid, A., Parpia, R. (2010). Relations between immigrant care workers and older persons in home and long-term care. Canadian Journal on Aging. 29(1), 109-118.

Brotman, S. (2002). The primacy of family in elder care discourse: Home care services to older ethnic women in Canada. Journal of Gerontological Social Work. 38(3), 1952 .

Brotman, S. (2003). The Limits of Multiculturalism in Elder Care Services. Journal of Aging Studies. 17(2), 209-229.

Canada, Parliament, Senate. Special Senate Committee on Aging. (2009). Canada's Aging Population: Seizing the Opportunity. Retrieved from: http://www.parl.gc.ca/Content/SEN/Committee/402/agei/rep/AgingFinalReporte.pdf. Retrieved on August 13, 2012.

Canadian Multiculturalism Act (1988, c. 24 (4 $4^{\text {th }}$ Supp.). Retrieved from the Department of Justice Canada website: http://laws-lois.justice.gc.ca/eng/acts/C-18.7/page1.html. Retrieved August 20, 2012.

Chappell, N. (2003). Correcting Cross-Cultural Stereotypes: Aging in Shanghai and Canada. Journal of Cross-Cultural Gerontology. 18, 127-147. 
Chung, J., Lai, C., Chung, P., \& French, H. (2002). Snoezelen for dementia. Cochrane Database of Systematic Reviews. 4, n.p.

Citizenship and Immigration Canada. (2011a). Facts and Figures 2010 - Immigration Overview: Permanent and Temporary Residents.

http://www.cic.gc.ca/english/resources/statistics/facts2010/permanent/04.asp.

Retrieved July 22, 2012.

(2011b). News Release - Government of Canada to cut backlog and wait times for faster family reunification - Phase I of Action Plan for Faster Family Reunification.

http://www.cic.gc.ca/english/department/media/releases/2011/2011-11-04.asp.

Retrieved April 2, 2012.

Coon, R. (1986). A theoretical examination of double jeopardy: Using theory as guide to concept analysis. Mid-American Review of Sociology. 11(1), 67-90.

Deri, C. (2005). Social networks and health service utilization. Journal of Health Economics. 24, 1076-1107.

Disman, M., \& Disman, M. (1995). Seniors, Culture and Institutionalization. In R. Neugebauer-Visano (ed), Aging and Inequality: Cultural constructions of differences (pp. 205-225). Toronto: Canadian Scholars Press.

Dowd, J.J., \& Bengtson, V.L. (1978). Aging in minority populations: An examination of the double jeopardy hypothesis. Journal of Gerontology. 33, 427-436.

Dunn, J. \& Dyck, I. (2000). Social determinants of health in Canada's immigrant popultion: results from the National Population Health Survey. Social Science \& Medicine. 51, 1573-1593.

Durst, D. (2005). Aging Among Immigrants in Canada: Population Drift. Canadian Studies in Population. 32(2), 257-270.

Friedman, D. (2006). Forsake them not: The Jewish community and elders in non-Jewish long-term care facilities. Journal of Jewish Communal Service. Spring, 149-155.

Gelfand, D. (2003). Aging and Ethnicity: Knowledge and Services ( $^{\text {nd }}$ ed.). New York: Springer.

Gelfand, D. \& and Kutzik, A. (1979). Ethnicity and Aging: Theory, Research and Policy. New York: Springer.

Gerrish, K., Husband, C. and Mackenzie, J. (1996) Nursing for a Multi-Ethnic Society. Buckingham: Open University Press. 
Green, A. \& Green, D. (2004). The goals of Canada's immigration policy: A historical perspective. Canadian Journal of Urban Research. 13(1), 102-139.

Green, L., Poland, B. and Rootman, I. (2000) The settings approach to health promotion. In B. Poland, L. Green and I. Rootman. (eds) Settings for Health Promotion: Linking Theory and Practice (pp. 341-351). London: Sage.

Harris, N. \& Grootjans, J. (2006). The potential role of ecological health promotion in progressing healthy ageing. Ageing International. 31(4), 276-282.

Harris, N., Grootjans, J., Wehham, K. (2008). Ecological aging: The settings approach to aged living and care accommodation. EcoHealth. 5(2), 196-204.

Holzberg, C. (1982). Ethnicity and Aging: Anthropological perspectives on more than just the minority elderly. The Gerontologist. 22(3), 249-257.

Jones, D. \& van Amelsvoort Jones, G. (1986). Communication patterns between nursing staff and the ethnic elderly in a long-term care facility. Journal of Advanced Nursing. 11(3), 265-272.

Kahana, E., Kahan, E., Sterin, G., Fedirko, T., Taylor, R. (1993). Adaptations to institutional life among Polish, Jewish, and Western European elderly. In C. Barresi \& D. Stull (eds), Ethnic elderly in long-term care (pp. 146-158). New York: Springer.

Kaida, L., Moyser, M., Park, S. (2009). Cultural preferences and economic constraints: The living arrangements of elderly Canadians. Canadian Journal of Aging. 28(4), 303-313.

Kaplan, D. \& Berkman, B. (2011). Dementia care: A global concern and social work challenge. International Social Work. 54(3), 361-73.

Kaplan, J. \& Shore, H. (1993). The Jewish nursing home: Innovations in policy and practice. In C. Barresi \& D. Stull (eds), Ethnic elderly in long-term care (pp. 113129). New York: Springer.

Kelley, N. \& Trebilcock, M. (2010). The Making of the Mosaic: A History of Canadian Immigration Policy ( $2^{\text {nd }}$ ed.). Toronto: University of Toronto Press.

Kim, S., Ehrich, J., Ficorilli, L. (2012). Perceptions of settlement well-being, language proficiency, and employment: An investigation of immigrant adult language learners in Australia; International Journal of Intercultural Relations. 36(1), 4152.

Lawton, M. (1977). An ecological theory of aging applied to elderly housing. Environments and Aging. 31(1), 8-10. 
Lai, D. \& Chau, S. (2007). Effects of service barriers on health status of older Chinese immigrants in Canada. Social Work. 52(3), 261-269.

(2011). The size of an ethno-cultural community as a social determinant of health for Chinese seniors. Journal of Immigrant Minority Health. 13, 1090-1098.

Lee, M. \& Mjelde-Mossey, L. (2004). Cultural dissonance among generations: A solution-focused approach with east Asian elders and their families. Journal of Marital and Family Therapy. 30(4), 497-513.

Leininger, M. (1988). Leininger's theory of nursing; Cultural care diversity and universality. Nursing Science Quarterly. 1, 152-160.

Lewis-Watt, L. (2006). Speaking with families from within the family class. Canadian Issues. Spring, 81-84.

Lundberg, P. (2000). Cultural care of Thai immigrants in Uppsala: A study of transcultural nursing in Sweden. Journal of Transcultural Nursing. 11(4), 274280.

McDonald, L. (2011). Rethinking theoretical and methodological issues in intergenerational family relations research. Ageing and Society. 31(7), 1180-1201.

Mausbach, B., Coon, D., Depp, C., Rabinowitz, Y., Wilson-Arias, E., Kraemer, H., ...Gallagher-Thompson, D. (2004). Ethnicity and time of institutionalization of dementia patients: A comparison of Latina and Caucasian female family caregivers. Journal of the American Geriatrics Society. 52, 1077-1084.

Ontario Long-Term Care Homes Act. (2010). Retrieved from the Government of Ontario e-laws website. http://www.elaws.gov.on.ca/html/source/regs/english/2010/elaws_src_regs_r1007 9 e.htm. Retrieved on July 22, 2012.

Rowles, G. (1980). Growing old "inside": Aging and attachment to place in an Appalachian community. In Datan, N. and Lohman, N. (eds.) Transitions of Aging. New York: Academic Press.

Schuster, E. (1996). Ethical considerations when conducting ethnographic research in a nursing home setting. Journal of Aging Studies. 10(1), 57-67.

Scott, A., Ryan, A., James, I., Mitchell, E. (2011). Perceptions and implications of violence from care home residents with dementia: A review and commentary. International Journal of Older People Nursing. 6(2), 110-122. 
Statistics Canada. (2007). 2006 Census: Immigration in Canada: A portrait of the foreign-born population, 2006 Census: Highlights. www.12.statscan.ca/censusrecensement/2006/as-sa/97-557/p1-eng.cfm. Retrieved August 15, 2012.

(2010). The Daily. May 26, 2010. Population projections: Canada, the provinces and territories. http://www.statcan.gc.ca/dailyquotidien/100526/dq100526b-eng.htm. Retrieved July 23, 2012.

(2012). The Daily. May 29, 2012. 2011 Census: Age and sex. http://www.statcan.gc.ca/daily-quotidien/120529/dq120529a-eng.htm. Retrieved August 17, 2012.

Stephens, C., Alpass, F., Towers, A., Stevenson, B. (2010). The effects of types of social networks, perceived social support and loneliness on the health of older people: Accounting for the social context. Journal of Aging and Health. 23(6), 887-911.

Stewart, M., Neufeld, A., Harrison, M., Spitzer, D., Hughes, K., Makwarimba, E. (2006). Immigrant women family caregivers in Canada: implications for policies and programmes in health and social sectors. Health and Social Care in the Community. 14(4), 329-340.

Treas, J. (2009). Four myths about older adults in America's immigrant families. Generations. 32(4), 40-45.

Treas, J. \& Mazumdar, S. (2002). Older people in America's immigrant families: Dilemmas of dependence, integration, and isolation. Journal of Aging Studies. 16, 243-258.

Wesley, J. (2011). Observing the political world: Qualitative and quantitative approaches. In K. Archer \& L. Berdahl (eds.) Explorations: Conducting empirical research in Canadian political science (pp. 123-144). Don Mills: Oxford University Press.

Wister, A., Pereira, I., Lazarowich, N. (1996). Ethnic content in long term care facilities for Portuguese and Italian elderly. Canadian Ethnic Studies. 28(2). 82.

World Health Organization. (2012a). Healthy Settings. www.who.int/healthy_settings/en/ Accessed April 15, 2012.

(2012b). Health statistics and health information systems: Definition of an older or elderly person.

http://www.who.int/healthinfo/survey/ageingdefnolder/en/index.html. Retrieved July 22, 2012.

Wright, R. \& Mindel, C. (1993). Economic, health, and service use policies: Implications for long-term care of ethnic elderly. In C. Barresi \& D. Stull (eds), Ethnic elderly in long-term care (pp. 247-263). New York: Springer. 
Wu, Z., \& Hart, R. (2002). Social health factors associated with support among elderly immigrants in Canada. Research on Aging. 24(4), 391-412.

Yang, F. \& Ebaugh, H. (2001). Transformations in new immigrant religions and their global implications. American Sociological Review. 66(2), 269-288.

Yeo, G. (1993). Ethnicity and nursing homes: factors affecting use and successful components for culturally sensitive care. In C. Barresi \& D. Stull (eds), Ethnic elderly in long-term care (pp. 161-177). New York: Springer. 